\title{
Smartphone Based Fall Prevention Exercises
}

\author{
Bruno Filipe Neves Ferreira
}

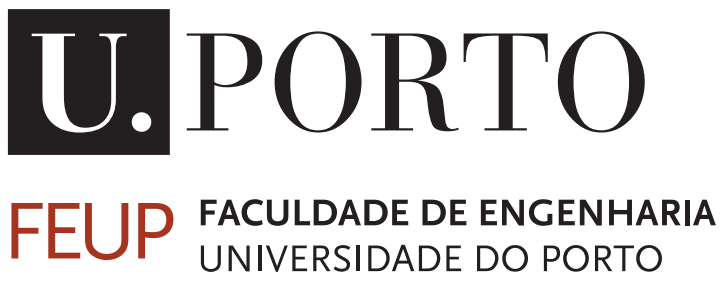

Mestrado Integrado em Engenharia Informática e Computação Supervisor: Hugo Sereno Ferreira $(\mathrm{PhD})$ 



\title{
Smartphone Based Fall Prevention Exercises
}

\author{
Bruno Filipe Neves Ferreira
}

Mestrado Integrado em Engenharia Informática e Computação

Approved in oral examination by the committee:

Chair: João António Correia Lopes (PhD)

External Examiner: José Carlos Baptista Nascimento e Silva (PhD)

Supervisor: Hugo José Sereno Lopes Ferreira (PhD)

July 11, 2013 



\section{Abstract}

Associated with ageing there is an increasing risk of serious problems, such as falls, affecting one out of three older adults and it is also the main cause of injuries.

Falls represents a large number of emergency situations reported to the health care providers. Loss of muscle mass, slowed pace of movement, decreased activity and some weight loss are just some of the factors that may lead to a fall.

In such advanced ages a fall may lead to serious individual and socioeconomic problems. Individual since, after a fall, the confidence of the person may decrease, being replaced by a fear, the fear of falling again, creating limitations in his/her daily life, such as a loss of independence. At socioeconomic level as these situations increase the costs related with health sector, becoming an important issue to our society.

This problem becomes even more important when analysing demographic data, which shows that the number of elderly people is increasing in our society. Therefore, it is an issue of extreme relevance to the society that requires attention.

Currently, this is a well-known problem and therefore multiple ICT-based solutions for falls prevention exist. In addition, a small part of them are said to help preventing falls, but most of the reviewed solutions doesn't seem to have their focus in reducing specific fall risk factors like muscle mass loss or poor balance.

The proposed fall prevention solution of this dissertation is based on an existing fall prevention programme specifically design to prevent existing fall risk factors, having as main goal the development of a solution capable of fulfilling the existing gap between the actual applications and the ability of performing fall prevention exercises regardless the user location.

Therefore, and taking advantage of the smartphone processing capabilities as well as of the inertial sensors built-in the smartphone (magnetic sensor, gyroscope and accelerometer), it is possible to develop an application that supports fall prevention exercises. Using only a simple smartphone it is possible to provide a friendly and inexpensive solution capable of increasing seniors' adherence to fall prevention exercises as well as raise their motivation to properly execute the exercises. Being an asset, not only for patients, but also for the healthcare providers.

The results achieved in this dissertation suggest that is viable the use of portable devices like a smartphone for evaluation and support of a set of fall prevention exercises, as well as for provide proper feedback about the exercise execution. Therefore, it appears that the developed project may be an value asset, not only for the elderly population, but also for the society. 


\section{Resumo}

À medida que uma pessoa envelhece vai aumentando o risco de sofrer problemas graves, como as quedas, que afectam um em cada três adultos, sendo a principal causa de lesões.

Grande parte das situações de emergência registadas pelos prestadores de cuidados de saúde resulta de quedas. Perda de massa muscular, redução de movimentos, diminuição da atividade física e alguma perda de peso são apenas alguns dos factores que as podem originar.

Quando ocorre uma queda, esta pode criar grandes entraves, tanto individuais como socioeconómicos. Individuais visto que, após uma queda, a confiança pessoal fica diminuída, dando lugar muitas vezes a um medo, o medo de voltar a cair, criando assim limitações na sua vida diária, tal como perda de independência. A nível socioecónomico aumentam os custos relacionados com a área de saúde, o que acaba por ter um grande impacto na sociedade.

Este problema torna-se ainda mais relevante e preocupante quando são analisados dados demográficos que mostram que o número de idosos na sociedade está a aumentar de ano para ano. Por tudo isto, este torna-se um tema que assume uma relevância particular, necessitando de especial atenção.

Hoje em dia já existem algumas soluções tecnológicas que procuram reduzir o elevado número de quedas e, consequentemente, os problemas que lhes são inerentes. No entanto, quando estas são analisadas, verifica-se que o seu foco de ação não se centra, concretamente, nos fatores de risco de queda existentes.

O projeto apresentado nesta dissertação baseia-se num programa desenhado especificamente para combater os riscos de queda existentes, tendo como principal objetivo desenvolver um sistema que complete o fosso existente entre as aplicações do mercado e a possibilidade de realizar os exercícios independentemente da localização do utilizador.

Deste modo, e tirando partido das capacidades de processamento de um smartphone, bem como dos sensores inerciais disponíveis no mesmo (como a bússola, o giroscópio e o acelerómetro), é possível desenvolver uma aplicação de suporte a exercícios de prevenção de queda. Assim, obtém-se uma solução eficaz e barata, capaz de aumentar a motivação dos idosos para a realização destes exercícios, que se apresenta como uma mais-valia, não só para os pacientes, como também para os responsáveis de saúde.

Os resultados alcançados nesta dissertação sugerem que é viável utilizar-se um dispositivo portátil, como um smartphone para avaliar e auxiliar a execução de exercícios de prevenção de queda, bem como, fornecer feedback acerca da realização dos mesmos. Neste sentido, verifica-se que o projeto desenvolvido pode trazer efetivamente mais-valias, não só para os idosos, como para a sociedade. 


\section{Acknowledgements}

Firstly I would like to express my honoured gratitude for both my supervisors Hugo Sereno Ferreira at FEUP, and Vânia Guimarães at Fraunhofer AICOS Portugal, for the constant support during the project, especially on documents writing. Their guidance and recommendations were essential to keep me on track.

Also, I would like to thank to therapist Cristina Melo for all of her support and willingness to help me understanding the exercises programme.

To my family and friends for their willingness to participate on this physically demand tests, whose contribution was vital for the final outcome. As well as for the support through these five years.

To Filipa, for her endless love, strength, support and patient especially when the journey didn't look good at all. Without her was impossible to accomplish this life project.

Finally, I want to, in a very special way, thank my parents and my sister for their infinite patience and support in the good and bad moments as well as for the endless days that they had to hear me.

Without every single person mentioned before, it would have been much more difficult to reach the end of this journey. My heartfelt gratitude to all of you.

Bruno Ferreira 
"If you're trying to achieve, there will be roadblocks.

I've had them; everybody has had them.

But obstacles don't have to stop you.

If you run into a wall, don't turn around and give up. Figure out how to climb it, go through it, or work around it."

Michael Jordan 


\section{Contents}

1 Introduction 1

1.1 Problem Statement . . . . . . . . . . . . . . . . . . . . 2

1.2 Initial Approach . . . . . . . . . . . . . . . . . . . 3

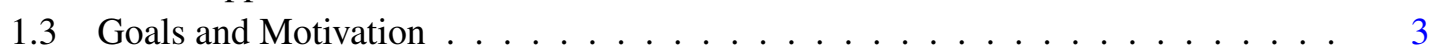

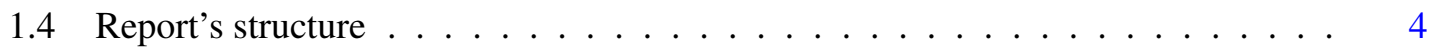

2 Fall Prevention Solutions 5

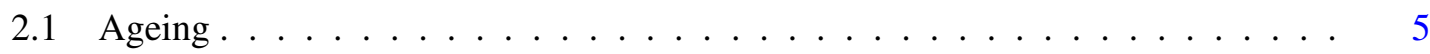

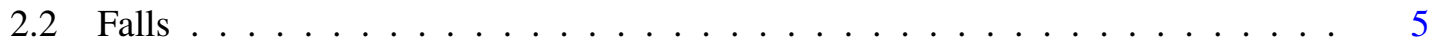

2.2.1 Fall Risk Factors . . . . . . . . . . . . . . . . . . . . 6

2.3 Falls Prevention . . . . . . . . . . . . . . . . . 7

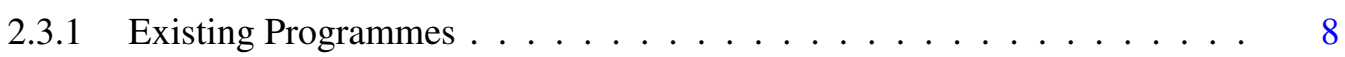

2.4 Summary and Conclusions $\ldots \ldots \ldots \ldots \ldots$

3 Existing Technological Solutions $\quad 13$

3.1 Smartphones . . . . . . . . . . . . . . . . . . . . 13

3.2 Android and Inertial Sensors … . . . . . . . . . . . . . . . 13

3.3 Signal Processing . . . . . . . . . . . . . . . . . . . . . . 15

3.4 Smartphones and Elderly . . . . . . . . . . . . . . . . . . . . . . 17

3.5 Existing Solutions . . . . . . . . . . . . . . . . . . . . . 17

3.5.1 SmartSenior's Interactive Trainer _ . . . . . . . . . . . . . . 17

3.5.2 Dance Dance Revolution . . . . . . . . . . . . . . . . . . 18

3.5 .3 NeuroGym . . . . . . . . . . . . . . . . . . . . . . . . . . 19

3.5 .4 Dance Don't Fall . . . . . . . . . . . . . . . . . . . . . . 19

3.5.5 Portable Acceleration Monitor Device . . . . . . . . . . . . . . . . 20

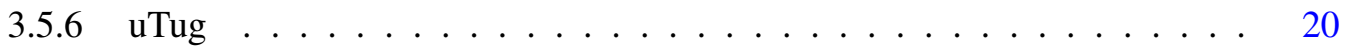

3.6 Summary and Conclusions $\ldots \ldots \ldots \ldots \ldots \ldots$

4 The Smartphone-Based Solution 23

4.1 Architecture . . . . . . . . . . . . . . . . . . 23

4.1.1 Data processing layer . . . . . . . . . . . . . . . . . 25

4.2 Smartphone Positioning . . . . . . . . . . . . . . . . . . 25

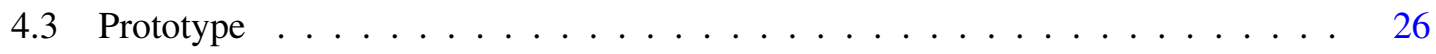

4.4 Movement Analysis . . . . . . . . . . . . . . . . . . . . . . 27

4.4 .1 Initial Analysis . . . . . . . . . . . . . . . . 28

4.4.2 Angle Between the Vertical and Smartphone Axis . . . . . . . . . . . 28

4.4 .3 Low-Pass Filter . . . . . . . . . . . . . . . . . . . . . 30 


\section{CONTENTS}

5 Exercise Processing 31

5.1 Extension of the Thoracic Spine . . . . . . . . . . . . . . . . . . . 31

5.2 Upper Limb Elevation . . . . . . . . . . . . . . . . . . . . . . . . . . . . 32

5.3 Plantar Flexion and Ankle Dorsiflexion . . . . . . . . . . . . . . . . . 34

5.4 Sit to Stand . . . . . . . . . . . . . . . . . . . . . . . 35

5.5 Single Leg Stance . . . . . . . . . . . . . . . . . . . . . . 37

5.6 Reaching Forward . . . . . . . . . . . . . . . . . . . . . 37

5.7 Evaluated Metrics . . . . . . . . . . . . . . . . . . . . . . 37

6 Validation and Evaluation 39

6.1 Evaluation Method . . . . . . . . . . . . . . . . . . . . . . 39

6.2 Results . . . . . . . . . . . . . . . . . . . . . . . 41

7 Conclusions and Future Work 49

7.1 Lessons Learned . . . . . . . . . . . . . . . . . . . . . 50

7.2 Future Work . . . . . . . . . . . . . . . . . . . 50

$\begin{array}{ll}\text { References } & 53\end{array}$

A Accepted Paper $\quad 57$ 


\section{List of Figures}

2.1 Relation between risk factors and falls. . . . . . . . . . . . . . . . 7

2.2 Otago Exercise Programme. . . . . . . . . . . . . . . . . . . . 9

2.3 Fame Programme. . . . . . . . . . . . . . . . . . . . . . 10

2.4 HBMI Programme exercises. . . . . . . . . . . . . . . . . . . . . 11

2.5 Stay Safe Stay Active fall prevention project. . . . . . . . . . . . . . . . 11

3.1 Android coordinate systems[Inc]. . . . . . . . . . . . . . . . . . . . . . 14

3.2 Accuracy and Precision[MS10]. . . . . . . . . . . . . . . . . . 16

3.3 Smartphone penetration by age group[GG12] . . . . . . . . . . . . . . 17

3.4 Dance Dance Revolution. . . . . . . . . . . . . . . . . . . . . . . . . . . . 18

3.5 NeuroGym Training System. . . . . . . . . . . . . . . . . . . . . . . . . 19

3.6 uTug application user interface. . . . . . . . . . . . . . . . 20

4.1 System Architecture. . . . . . . . . . . . . . . . . . . . . . . . . 24

4.2 Data processing layer components. . . . . . . . . . . . . . 25

4.3 Possible Smartphone Locations. . . . . . . . . . . . . . . . . . . . 26

4.4 Smartphone Final Locations. . . . . . . . . . . . . . . . . . . . . . 27

4.5 Solution Interfaces. . . . . . . . . . . . . . . . . . . . . . . . . . . 29

4.6 Upper Limb Elevation recorded with accelerometer. . . . . . . . . . . . . . . . . 29

4.7 Android axes and gravity vector. . . . . . . . . . . . . . . . . . 30

5.1 Extension of Thoracic Spine recorded with accelerometer and linear acceleration

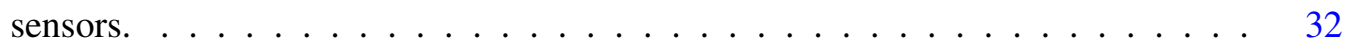

5.2 Exercise execution illustration. . . . . . . . . . . . . . . . 33

5.3 Upper Limb Elevation recorded with gravity and rotation vector sensors. . . . . . 33

5.4 Plantar flexion and Ankle Dorsiflexion execution illustration. . . . . . . . . . . . 34

5.5 Plantar Flexion recorded with gravity sensor. . . . . . . . . . . . . . . 35

5.6 Sit to Stand recorded with gravity sensor. . . . . . . . . . . . . . . . 36

5.7 Single Leg Stance recorded with gravity sensor. . . . . . . . . . . . . . . . . 36

5.8 Reaching Forward recorded with gravity and linear acceleration sensors. . . . . . 37

5.9 Reaching forward exercise illustration. . . . . . . . . . . . . . . . . . . 38

6.1 Tests Scenario. . . . . . . . . . . . . . . . . . . . . . . 40

6.2 Illustration of the angle performed between the arm and vertical. . . . . . . . . . 41

6.3 Comparison between the number of forced positions on the smarphone and on the video values in Upper Limb Elevation. . . . . . . . . . . . . . . . . . . . . 43

6.4 Comparison between the number of forced positions and angle values on the smarphone and on the video values in Extension of Thoracic Spine. . . . . . . . . . . 43 


\section{LIST OF FIGURES}

6.5 Comparison between the angle values on the smarphone and on the video values in Reaching Forward. . . . . . . . . . . . . . . . . . . 46

6.6 Comparison between the execution time on the smarphone and on the video values in the complete cycle of Sit to Stand. . . . . . . . . . . . . . . . . . .

6.7 Comparison between t execution time on the smarphone and on the video values in Sit to Stand and Stand to Sit. . . . . . . . . . . . . . . . . . . . . . . 


\section{List of Tables}

3.1 Solutions comparative. . . . . . . . . . . . . . . . . . . 21

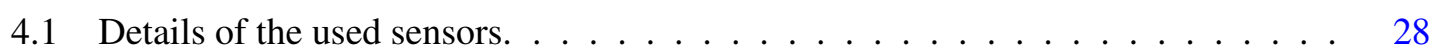

5.1 Metrics collected in each exercise. . . . . . . . . . . . . . . 38

6.1 Upper Limb Elevation statistic. . . . . . . . . . . . . . . . . . . . . . . . . 42

6.2 Extension of Thoracic Spine statistic. . . . . . . . . . . . . . . . . . . 44

6.3 Reaching Forward statistic. . . . . . . . . . . . . . . . . . . . 45

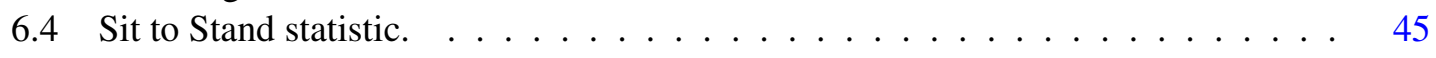


LIST OF TABLES 


\section{Abbreviations}

$\begin{array}{ll}\text { HBMI } & \text { Home Based Moderate Intensity } \\ \text { FAME } & \text { Fitness and Mobility Exercise } \\ \text { DDF } & \text { Dance Don't Fall } \\ \text { DDR } & \text { Dance Revolution } \\ \text { EMG } & \text { Electromyography } \\ \text { PAMD } & \text { Portable Acceleration Monitor Device } \\ \text { SSIT } & \text { SmartSenior's Interactive Trainer } \\ \text { GPS } & \text { Global Positioning System } \\ \text { USB } & \text { Universal Serial Bus } \\ \text { ACC } & \text { Accelerometer } \\ \text { Grav } & \text { Gravity } \\ \text { Lacc } & \text { Linear Acceleration } \\ \text { RotVector } & \text { Rotation Vector } \\ \text { Std. } & \text { Standard }\end{array}$





\section{Chapter 1}

\section{Introduction}

We live in a period in which the number of people living until older ages is increasing. This increase of life expectancy is usually seen as good situation to the society as it reflects the evolution of life quality as well as the improvements made in medicine. But with an older population new problems arise, these problems are mainly social and economical. Therefore ageing must be seen as a problem that needs to be solved in order to improve the life quality of the elderly people as well as to reduce society costs that are directly connected with ageing.

The main problems that are directly associated with ageing are falls and frailty, being both extremely relevant to the society [fDCP12]. It is also known that one out of three seniors experience a fall each year[fDCP12]. Falling in such advanced ages may lead to serious injuries like fractures or head injuries, even the lighter falls are prone to require medical attention. This represents a huge economic impact on society, being directly associated with health care costs that are particular high when the person needs to stay in a hospital for an extended period of time, or more common when the intervention of the emergency department is required [fDCP12, Org07].

With such drawbacks it is important to find solutions capable of reducing the number of falls among older people, otherwise it will become a massive problem to the society. One of those solutions are physical exercises. Physical exercises are known to improve older person's muscle mass, increase muscle strength, and more importantly, improve balance. Currently, several exercise programs exist and are suitable to be performed by the older person alone or in group, without compromising their safety [tpfioa03, FAM06, AdMC11].

Unfortunately, fall prevention exercises are rarely applied. This occurs due to the high costs of transportation to clinical environments where group exercises are performed, usually in a daily or weekly basis $\left[\mathrm{HOT}^{+}\right.$09, Org07]. Furthermore, when the senior is alone at home, he/she does not have the motivation required to perform these tiresome exercises.

Having these problems in mind it is necessary to find solutions for increasing the adherence to fall prevention exercises, and also to increase the awareness about the benefits that these exercises represent to the older person, increasing their motivation and the "treatment" compliance. 
Introduction

One of these solutions can be achieved by using today's technologies, like smartphones, devices that have high levels of mobility and usability and are at the same time extremely powerful. Additionally, smartphones have built-in sensors that can be used to evaluate movements performed by the user. Therefore, these kind of devices can be used to create a solution capable of motivate, explain and evaluate the user performance in fall prevention exercises.

\subsection{Problem Statement}

In order to reduce the number of falls we need to focus in the root of the problem. The loss of muscle mass, a slowed pace of movements, weight loss and an obvious decrease of activity $\left[\mathrm{HOT}^{+} 09\right]$ are just some of the reasons that may lead to unintentional fall. Risks factors for falling can be early detected, and specific fall prevention strategies can be applied in order to reduce or modify those risks. A common strategy to prevent falls is the application of physical exercises, targeting specific risks for falling.

Physical exercises will improve the older person's muscle mass, increase muscle strength, and more importantly they will improve balance. These exercises can be performed either in a clinical environment with the help of specialists as well as at home or institution. In other to be performed at home these exercises must be simple, practical to perform and always available, but above all they should be safe to the patient. But, unfortunately, fall prevention exercises are weakly applied.

There are already a few fall prevention programmes designed to be performed without any kind of external devices, but these programmes have a big handicap: they have no way to efficiently evaluate the exercise performance and, at the same time, keep the user motivated without the constant support of an occupational therapist, as when the elderly is alone at home he/she does not have the motivation required to perform continuously these tiresome exercises.

Therefore it is important to fill this gap with a solution that enables older persons to perform correctly a set of fall prevention exercises, evaluate their performance as well as keep them motivated through time.

The first point that needs to be fulfilled is the exercises availability that should be always available for elderly people living at home or institutionalized. This constant availability is crucial for the success of the exercises as well as for the user motivation, and can be achieved using portable technology.

In addition to it, it is important to accurately evaluate movements' performance during the exercises execution. This evaluation must be done on the least intrusive way possible but at the same time it must be precise. Moreover if we are unable to collect and properly analyse the information from the exercise we are unable to help the user to improve his/her performance and therefore to reduce their risk of falling.

This leads to another important point, that is how to keep the users motivated with the exercises through a long period of time. Motivation is essential to the effectiveness of the exercises, since they become more efficient if they are repeatedly performed. Therefore, the user needs to keep the same motivation he had months before, when he used the application for the first time. 
Finally, but no less important it is necessary to find a way to collect metrics that can be used for further medical analysis. This analysis is extremely important to provide feedback to the patient. Additionally, it is important to find a way to encourage the realization of preventing exercises, and also make them easy to perform regardless the location of the elderly, i. e., do not restrict the place where exercises can be executed to the place where the technology or equipment is installed.

\subsection{Initial Approach}

To define the best approach to solve the problem stated, it was necessary to analyse the different set of technologies available today. One of these technologies are the modern video game consoles, that through external devices are able to identify and process the users' movements. Therefore, they can be seen as a means to help and support users through fall prevention exercises at their homes or institutions. However, it will restrict the exercises execution to the place where the console is. Moreover a console can be quite expensive to be used as a facilitator of fall prevention exercises.

Another available technology are the computers, or, preferably, due to its portability, the laptops which overcomes one of the consoles handicap [Whi90, $\mathrm{SSS}^{+} 11$ ]. The main disadvantage is that they require the connection of external devices to detect user movements and consequently an additional configuration step, which might reduce the usability and increase the costs of the whole system.

Taking a deeper look into the technologies in vogue and the smartphones and tablets emerge as a very interesting solution. Both devices are extremely similar, but due to its dimensions, the smartphone is more likely to fulfil all the needs, as it can be easily attached to the body. They are also cheap, and most importantly they are extremely portable and include a set of inertial sensors which can be used to evaluate the user's movements. The smartphone is very popular and most people have already one, therefore, the smartphone was chosen as the basis of this project.

\subsection{Goals and Motivation}

We are living in austerity times where the health sector is also affected by economic restrictions and problems. Therefore, is crucial to find cheaper solutions for improving the life quality of the population, in this specific case the life quality of older adults. Moreover, this becomes increasingly important to the society due to the expected increase of this population segment in the upcoming years.

Due to the high number of falls experienced by the elderly population, it is clear that falls affects directly their life, especially when they get injured and therefore need rehabilitation. The period of rehabilitation after a fall can be very long and hard to the person and to the physiotherapist. The person may suffer from pain and, in order to be committed with the rehabilitation process, several transportations to the clinics are required, which is also cumbersome. 
With such drawbacks to the older population it is rewarding developing a solution that is capable of guiding an elderly person throughout a set of fall prevention exercises in a safe and easy way. In addition, it is important that the application can correctly evaluate and provide feedback about the user performance.

One advantage of the proposed system is it uniqueness, as the current solutions in fall prevention require specific equipment like sensors, and therefore becomes very expensive. On the other hand a simple smartphone is accessible to everyone, becoming a cheap solution that already includes the required inertial sensors and high processing power. A smartphone is also a portable solution, enabling the user to perform the exercises more frequently.

The aim of this project is therefore to help both patient and medical professionals in the correct and repetitive execution of fall prevention exercises, as well as their evolution. Using the sensors provided by a single smartphone, it must be capable of collect and process the information regarding the exercise execution, which enables the medical professionals and patients to analyse their evolution through time.

\subsection{Report's structure}

This report has seven chapters, the Introduction (Chapter 1) where the problem is exposed, as well as motivations and objectives of the developed work.

The second chapter (Chapter 2) is related to the current state of the art regarding falls and fall prevention programmes. While the chapter 3 addresses to the existing technological solutions.

The next chapter, The Smartphone-Based Solution (Chapter 4), describes the system architecture, problem approaches as well the implemented prototype.

The fifth chapter (Chapter 5) addresses to a description the exercises evaluation.

On chapter 6 is presented the validation of the algorithms implemented as well as some considerations regarding the chosen evaluation.

The last chapter (Chapter 7) has a description some potential future work, and the conclusions of this project are presented. 


\section{Chapter 2}

\section{Fall Prevention Solutions}

The aim of this chapter is to provide an overview of the state of the art regarding falls and fall prevention techniques. After exploring some fall concepts, are described some existing fall prevention programmes.

\subsection{Ageing}

Ageing is one of the biggest problems faced by our society. With the increase of life expectancy, it is projected that in $201518,7 \%$ of European population will have more than 65 years old, against $15,6 \%$ of young people. Furthermore, this gap tends to increase through the upcoming years with the index of ageing growing up from 120 in 2015 to near 200 in 2050 [INdE12].

Associated with an ageing population, new social and economic problems arise, which constitutes a challenge for our society. Particularly, falls are a serious and common problem that affects older persons, as this age group is particularly prone to falls and injuries.

\subsection{Falls}

Falls are a very serious problem to our society, especially to the elderly population. It is known that one out of three seniors experience a fall each year [fDCP12, WH91], and this number rises to nearly $50 \%$ when we are talking about institutionalized people [Org07]. In addition to it, $40 \%$ of people who fall have already fallen before. It is also important to be aware that the number of falls rises exponentially with age and it is higher in women than in men $\left[\mathrm{GOH}^{+} 96\right]$.

Between $20 \%$ and $30 \%$ of those who fall suffer injuries that reduce mobility and independence [TS04]. Falling is an occurrence that may lead to serious consequences like injuries, psychological difficulties or social isolation $\left[\mathrm{GOH}^{+} 96\right]$.

A fall can be defined as a loss of balance, but for healthcare professionals it is an event that may lead to serious injuries [Org07]. In other words it is "an event which results in the person 
coming to rest inadvertently on the ground or other lower level, and other than as a consequence of the following: sustaining a violent blow, loss of consciousness, sudden onset of paralysis, or an epileptic seizure" [Org07, TS04].

However, older people do not see it as a critical event and therefore less than $50 \%$ report the falls to their healthcare provider [fDCP12]. Despite this lack of report elderly are apprehensive about falls and this fear of falling may compromise their life quality by diminishing the sense of well being, limiting mobility and reducing social interaction [WH91].

Falling in this advanced ages can lead to serious injuries like hip fracture or head injury as well as pneumonia and dehydration. Dehydration may occur when the elderly is unable to get up from the ground, by himself and he/her is alone at home [HOT $\left.{ }^{+} 09\right]$. Often, falling becomes a pain at personal level, and restricts the older person's personal life at about 20\%, which can last for several months. This occurs due to a physical decay and to a fear of falling again [HOT $\left.{ }^{+} 09\right]$.

Over $90 \%$ of hip fractures are caused by a fall, they are also the sixth cause of death among older people and the leading cause of accidental death at home, in addition it represents a frequent factor for admission in nursing homes. [WH91, $\mathrm{HOT}^{+} 09$ ]. Falls also may lead to head traumas or some type of fractures, and about $5 \%$ of the falls results in a fracture $\left[\mathrm{GOH}^{+} 96\right]$.

Another matter associated to falls is the high costs to society, as falls represent $15 \%$ of all emergency department visits as well as $6 \%$ of all health care expenses. These costs may raise rapidly when older people have a fracture as they tend to stay at hospitals for extend periods of time. These periods can be around 20 days when we are talking about a hip fracture [Org07, $\mathrm{HOT}^{+}$09].

\subsubsection{Fall Risk Factors}

In order to reduce the number of falls, it is important to identify the most common fall risk factors and apply specific fall prevention strategies to reduce those risks.

Falling can be considered a multifactorial problem due to both extrinsic and intrinsic risk factors, but usually it is combination of factors that leads to a fall $\left[\mathrm{GOH}^{+} 96\right]$. An extrinsic factor concerns every aspect that is external to the patient like environmental and house conditions, on the other hand the intrinsic risk factors are directly related with the patient, like the health condition or his/her behaviours.

With the increasing age, the quality of vision starts to decrease and consequently the risk of falling rises considerably, as we cannot have the adequate perception of the reality. More physical problems arise with ageing, namely the decline of muscle endurance and strength, loss of flexibility, reduced balance as well as the decline of the voluntary stepping time (Figure 2.1) [AdMC11].

Additionally, some of medication prescribed, especially the sedatives may increase the fall risk once the patient is more dormant. In some situations these risks are augmented due to an impaired cognition.

Finally, it is important to understand which periods are more prone to the occurrence of falls. These periods are the periods of increased activity, like the meals time or the morning period 


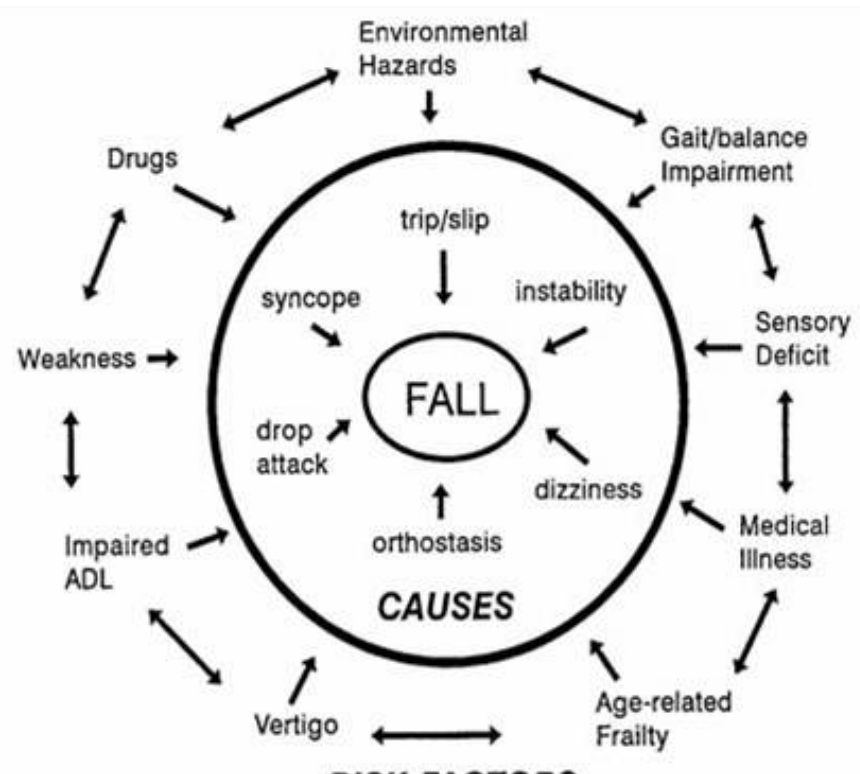

RISK FACTORS

Figure 2.1: Relation between risk factors and falls.

when the elderly wakes up, and therefore during these periods the older person is more exposed to risks[WH91].

An effective strategy to prevent falls is the practice of physical exercise, preferably targeting specific fall risks factors.

\subsection{Falls Prevention}

Falls is a serious problem that must be taken into account, being essential to prevent falls, otherwise the number of falls will increase over the next 25 to 30 years [TS04].

A wide range of strategies can be used to prevent falls on older people, both on people who have never fallen and those who have experienced a fall before $\left[\mathrm{GOH}^{+} 96\right]$. Fall prevention should focus on four main components, i.e., education, environmental safety, risk-taking behaviours, assertiveness training and physical fitness [WH91].

\section{Education}

Elderly do not see falls as a critical event or are reluctant to discuss their fall experience and therefore less than 50\% report the falls to their healthcare provider [fDCP12]. This situation occurs due to the idea that falling is an inevitable consequence of ageing, but this idea must be overcome and replaced by the idea that falls can be prevented by awareness of the problem and modification of environmental and behavioural risk factors. [WH91]. 
Environmental Safety

Home hazard assessment and modification may look simple at first, but it is also very effective to prevent falls. Elderly can be guided in identifying and eliminating environmental hazards in their homes. This can be as simple as rearrange the furniture, avoid poorly lit areas and chairs on casters as well as challenging movements and tasks, which is a frequent cause of a fall $\left[\mathrm{KSP}^{+} 05\right.$, WH91].

Risk-taking behaviours

During their daily lives most of the elderly are not aware of the risks of some of those activities, therefore it is important to taught them to recognize risky situations and how to approach them in a safer way. For example, instead of using a step tool to reach overhead item, they should place them in a easy reachable place [WH91].

\section{Physical Fitness}

Physical exercises are essential to improve the quality of life in older population, especially exercises designed for fall prevention that can be provided by occupational therapists and be performed at home with low-risk. These exercises may improve balance and muscle strength and may also increase bone mineral density $\left[\mathrm{GOH}^{+} 96\right.$, WH91]. It is also known that balance exercises are $25 \%$ effective to prevent falls [SLC08].

Resorting to these kind of exercises it is possible to reduce the normal fall rates of an elderly person between $30 \%$ and $40 \%$ [OYY ${ }^{+} 10$ ]. But in order to become more effective in fall prevention these exercises should be performed at least during 2 hours a week, for a period of 6 months [SLC08].

\subsubsection{Existing Programmes}

There are already a few effective fall prevention programmes, with given evidences in the field. These programmes have their focus on improving the patient strength, flexibility, balance and reaction time, as they are considered the most readily modifiable risk factors for falls. Moreover it is known that even people with more than 90 years old can improve their strength and balance in order to achieve stability and therefore avoid falls [tpfioa03].

\section{Otago Exercise Programme}

The Otago Exercise Programme is set of strength and balance retraining exercises with a gradual increase of difficulty and a walking plan. A single session of this programme takes about 30 minutes, and the participants are expected to perform the exercises three times per week and go for a walk at least twice a week (Figure 2.2).

One of the limitations of this programme is the necessity of acquiring an external object, the cuff weights. Another inconvenience of this programme is that an instructor must perform five home visits, or a phone call each month between home visits. Each visit occurs from 


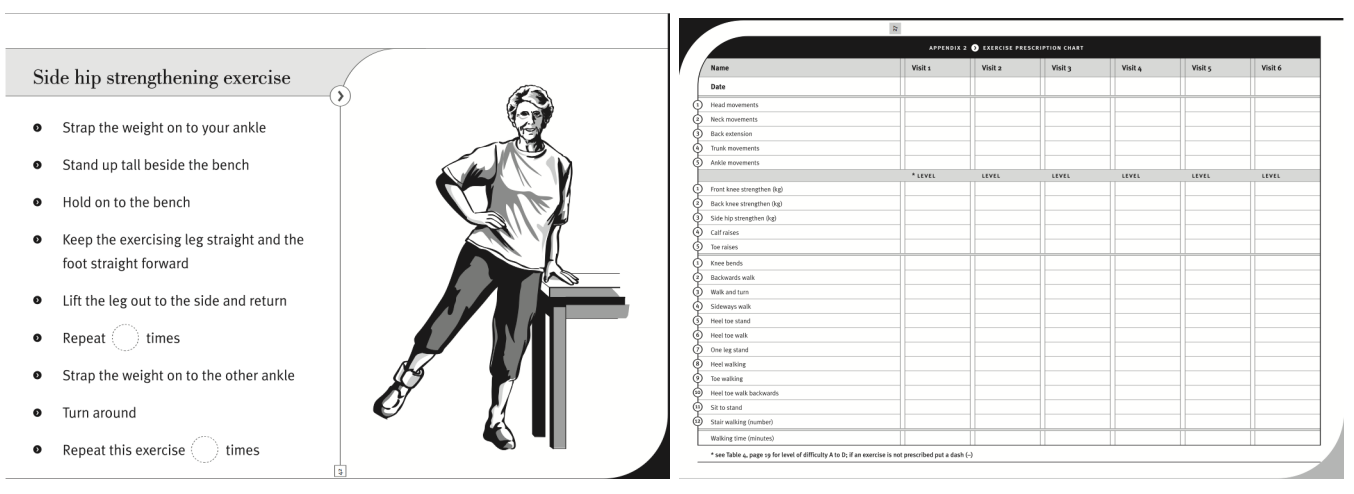

Figure 2.2: Otago Exercise Programme.

six to six months at least, and during this period it is expected that participants record their exercises every time they perform them.

This programme accomplished to reduce in $35 \%$ the number of falls and injuries, equally among men and women [tpfioa03].

\section{FAME Programme}

Another programme is the Fitness and Mobility Exercise (FAME) Programme designed to be performed in a hospital, gym or in a day care facility. The first objective of this programme is to optimize the physical ability of people living with a stroke, and at the same time minimize secondary complications such as falls and fractures (Figure 2.3).

This programme requires stables chairs, steppers and, as in the Otago programme, it requires weights to be able to progress on exercises difficulty. The FAME programme is also focused in improving multiple domains like balance, muscle strength, bone health and mobility.

One important aspect of this programme is the participants' motivation, as it was developed to be performed in group, being essential to enhance the participants adherence to the program and at the same time be socially stimulating.

A ten weeks trial of this programme, resulted in a faster postural reflexes as well as $30 \%$ decrease of falls in participants who had already fallen before. Each programme session has the duration of one hour, and it is recommended to perform the exercises three times per week, during a period of three to four months [FAM06].

\section{A preventive, specific and moderate exercise programme on fall risk factors in older por-} tuguese people

The Home Based Moderate Intensity (HBMI) Exercise Programme is another programme that has his focus in improving balance and muscle strength, more specifically on the lower limb strength, muscle endurance and flexibility of spine and ankles as well as voluntary stepping (Figure 2.4). 


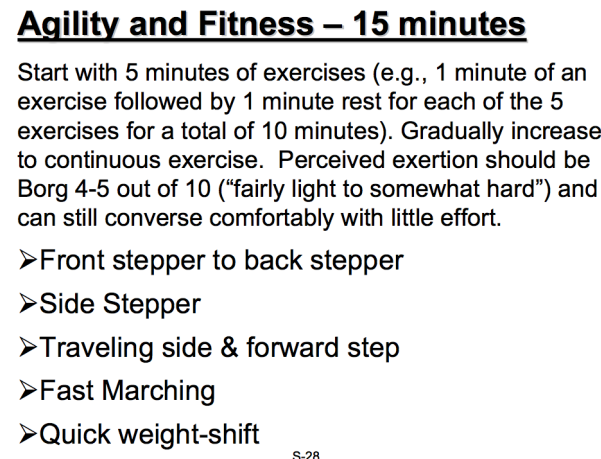

Figure 2.3: Fame Programme.

The principal advantage of this programme is that it can be performed without any equipment, and the evaluation of the progression is made by comparison with specific baseline exercises. Like most fall prevention programmes the recommended duration of HBMI is nine months and it is designed to be performed at home without external support. This approach poses some problems regarding motivation, as some of the participants do not perform the exercises spontaneously, as required.

Being easy to understand, easy to perform, not requiring equipment and being specifically focused on fall risk factors, this programme has proven to increase the quality of life of the participants as well as directly improving the fall risks factors like ankle flexibility, lower limb strength and balance. Additionally it improves functional activities and includes a walking programme to increase cardiovascular endurance [AdMC11].

\section{Stay Safe Stay Active}

As the previous fall prevention programmes, the Stay Safe Stay Active as its focus in improving balance and coordination, muscle strength, reaction time and aerobic capacity. Being therefore a very complete programme.

It has a set of modified Tai Chi exercises aimed to into improve balance, while the strengthening exercises are performed using only the participant's weight. Additionally it have include a fast-walking practice that aims to improve aerobic capacity (Figure 2.5).

This programme was designed to be performed in group sessions held in community settings, with additional home exercises. Each group session is held once a week, within a total of 37 sessions during a year. Each session has the duration of one hour [BA03]. 

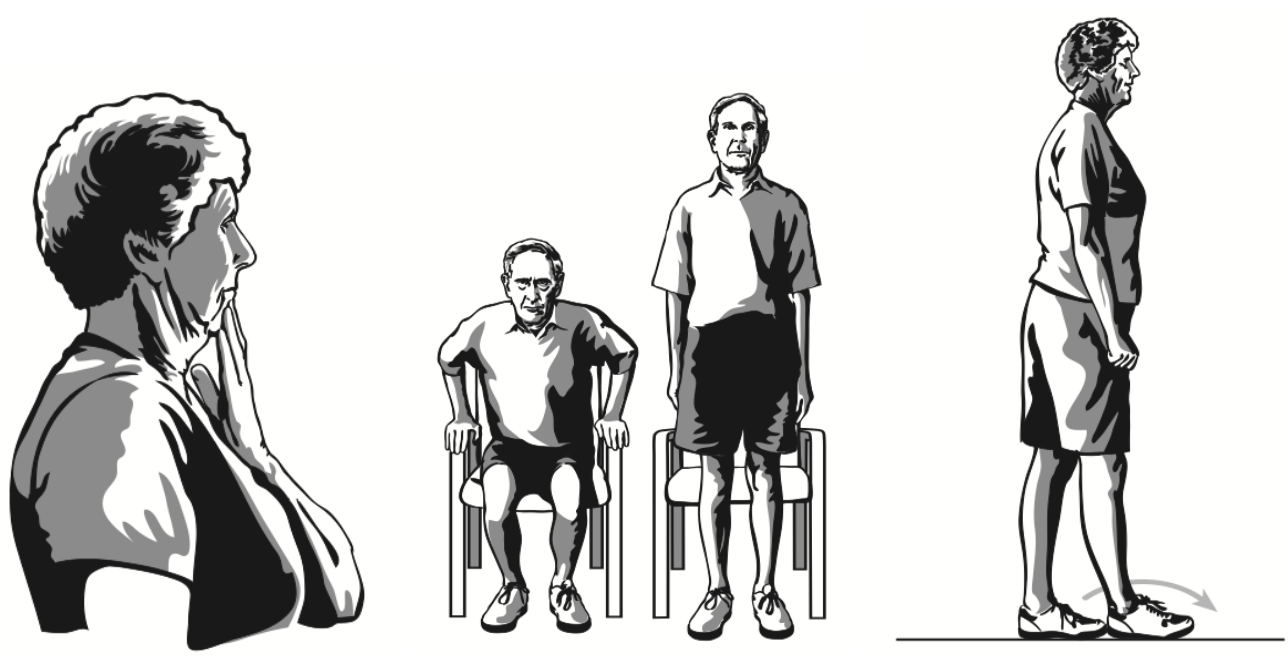

Figure 2.4: HBMI Programme exercises.

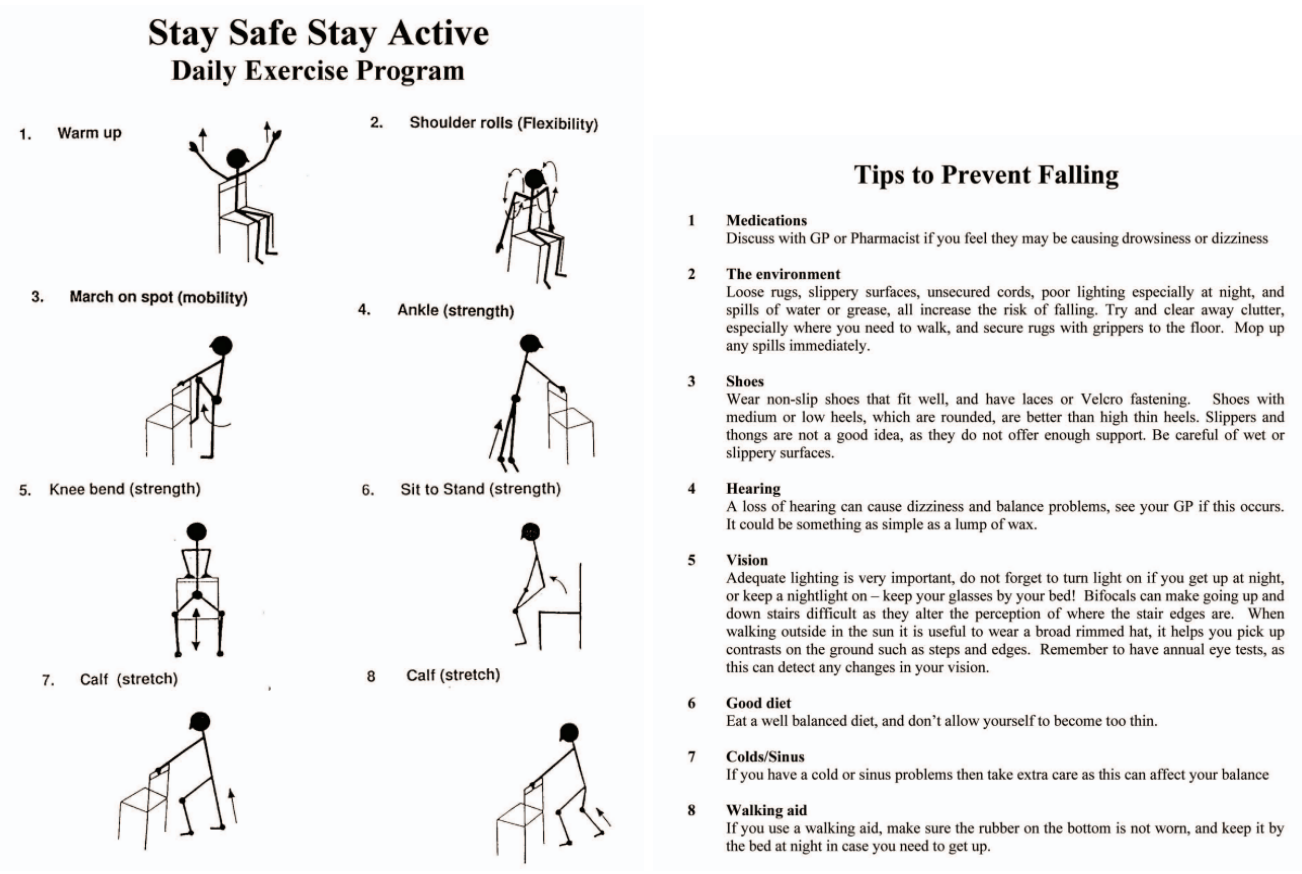

Figure 2.5: Stay Safe Stay Active fall prevention project. 
Fall Prevention Solutions

\subsection{Summary and Conclusions}

Falls are a serious problem that affects large part of the elderly population; therefore it is necessary to apply fall prevention programmes. The existing fall prevention programmes are extremely efficient in reducing specific fall risk factors, but they require a direct support provided by the health care providers.

Despite that, these programmes have a common drawback, the user motivation and the costs associated with a constant need of support. In order to reduce these drawbacks there are already few technological solutions (Chapter 3), but none of them with the main goal of improving the actual state of the fall prevention programmes. 


\section{Chapter 3}

\section{Existing Technological Solutions}

Based on the current state of the art, fall prevention exercises can be performed using different tools, techniques and approaches. In this project is suggested a new approach to the actual solutions, this approach suggest the use of a smartphone to support, guide and evaluate existing fall prevention exercises.

In this chapter, existing similar solutions are presented as well as the platform chosen to support the entire solution taking into account the target population of this project.

\subsection{Smartphones}

The number of smartphones is increasing at very high rates. In 2012 the penetration rate of smartphones in the world were about $24 \%$, and it is expected that in 2016 this rate will increase up to 45\%. This number raises up to $73 \%$ in North America and $71 \%$ in Europe. [eMa13]

In addition to these high rates of penetration, it is known that since 2011 fewer computers are shipped when compared to smartphones. In 2011, 498 million smartphones were shipped and only 415 million computers [McK12], while in the third quarter of 2012 the computers sales dropped over $8 \%$ [Bha13].

In 2012 the device preferred to access the internet was the smartphone. With over a billion of smartphones around the world it was also the preferred device for the most common tasks like listening to music, watching video or social networking [Bha13].

Smartphone massification is an opportunity to create and delivery solutions to nearly everyone, once these devices are extremely powerful and can provide a solution to several complex tasks.

\subsection{Android and Inertial Sensors}

Android is a platform which provides a wide set of tools that enable a full exploration of the smartphone capabilities. Android is an open source and free development platform based on 


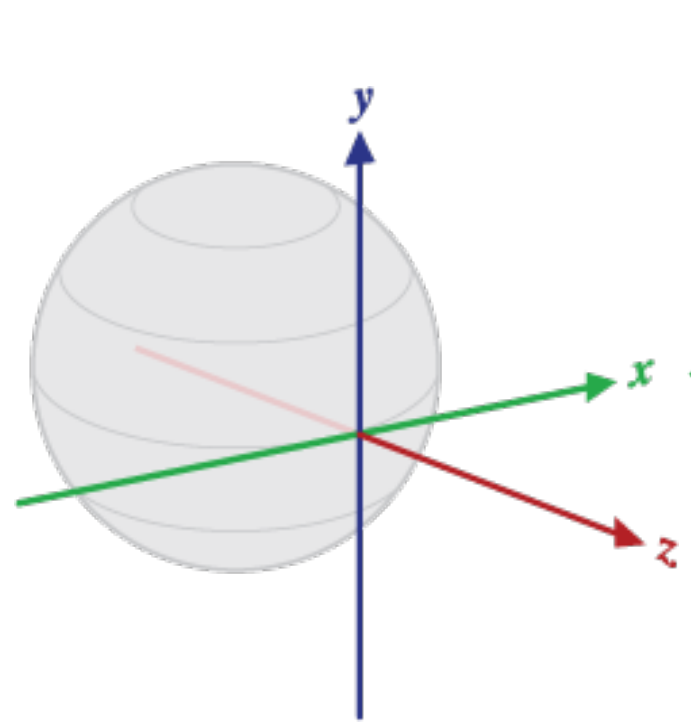

(a) Global coordinate system

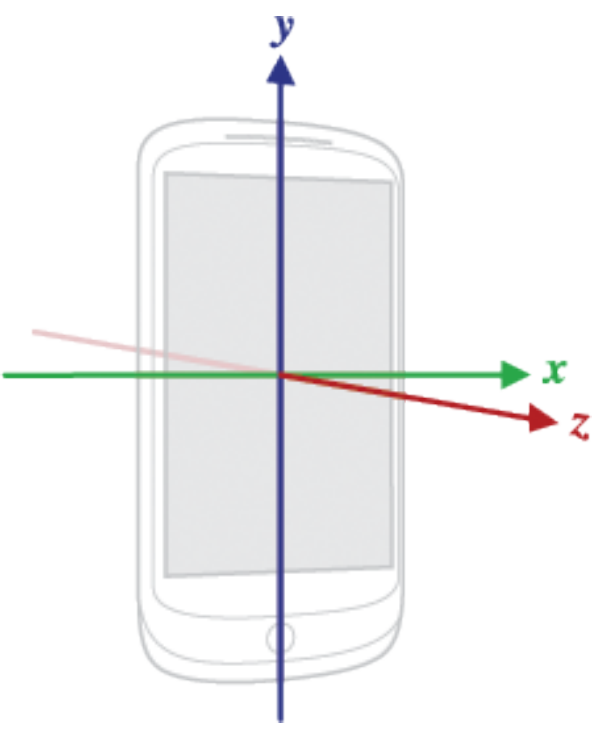

(b) Device coordinate system

Figure 3.1: Android coordinate systems[Inc].

Linux. The Linux kernel is the base of the whole platform and it is responsible for memory and process management, as well as networking and others system services on Android [Bur10]. Android is one of the most popular platform in the world, having already millions of users and more than 600 thousand of applications [Goo13].

It also has a lot of built-in services out of the box like the GPS, gyroscope, accelerometer and magnetic sensor. In addition to it, Android offers portability for current and future hardware. This portability is only possible because all of the programs that run in Android are written in Java and are executed by a virtual machine called Dalvik [Bur10]. This virtual machine is optimized to compile Java class files taking into account the device limitations such as memory, processor speed and power [SH11]. This design makes possible to write Java code to be run on the device and therefore it is very easy to create Android-based programs.

Android devices has two coordinate systems: one to represent the global coordinate system (i.e. the Earth) (Figure 6.4a) and one to represent the device coordinate system (Figure 6.4b). Inertial sensors are designed to measure motion. Accelerometer, gyroscope and magnetometer are some examples of sensors usually available in Android devices [MS10].

- The accelerometer, can sense tri-axial accelerations. The accelerometer on Android is a set of tiny masses on tiny springs. These springs bend whenever an inertial force acts, being able to measure it. It can measure the forces applied to the device, either the earth's gravity or the forces resulting from shaking the device [MS10].

- Gyroscope, like the accelerometer, it constituted by a set of tiny masses on tiny springs. In this case, instead of measuring the acceleration they measure the rotation force, or the Coriolis force. The Coriolis force acts only when the device is rotating, which enables the 
measurement of the speed rotation of the device. It is not possible to measure directly the angle of the device using the gyroscope, unless these values are integrated over time. When the device is stationary the gyroscope will measure zero [MS10].

- Magnetometer is a quite complex sensor, and depending on the manufacturer and architecture it may be implemented using the Hall effect, Lorentz force or even magneto-resistive materials. The most common solution is the Hall effect that consists in passing current through a wire. Magnetometers, like the compass, are used to measure the absolute magnetic field of the Earth. The values measured by the magnetometer change based on the current local magnetic environment [MS10].

In addition to these sensors, Android has some built-in sensor fusion techniques available by software and/or hardware. Sensor fusion is a process of combining multiple sensors data in order to obtain more accurate results [MS10]. With these techniques it is possible to smooth the noise produced by sensors like the accelerometer, or compute the device's orientation relative to the Earth. In this sense, accelerations due to gravity can be discriminated from those due to movement (resulting in the linear acceleration sensor), therefore improving the accuracy of measurements.

On Android the result of sensor fusion is used as a sensor, e.g. the gravity sensor that gives the value of the gravity after being processed according to the accelerometer readings. Another sensor that results from a sensor fusion technique is the rotation vector, which provides the device orientation as a combination of an angle and an axis, in which the device has rotated through an angle around an axis [Inc]. Modern devices include virtual or hardware sensors capable of measuring data with respect to the global coordinate system.

\subsection{Signal Processing}

The sensors available on Android, like most of the existing sensors, do not measure values perfectly, once the sensor's readings can have inaccurate values due to noise or degradation over time. Therefore when using sensor's it is essential to have in mind these two problems, in order to reduce the errors produced by the sensors.

There are also different types of errors when processing sensor data, namely, human errors produced for example when analysing a set of measurements. Systematic errors, also affect the accuracy of the data and they can be produced by adding a constant offset to the original values [MS10].

When using the available sensors on Android it is important to have in mind another type of errors, namely the zero offset, similar to the systematic errors but in this case the error can occur, for example, when a device is flat on a table and the values read by the $\mathrm{X}$ and $\mathrm{Y}$ axes are not equal to zero. This particular error can be reduced with calibrating the signal when the smartphone is totally flat. As Android is not a real-time operating system, some of the readings can have incorrect timestamps, or in other situations some data may be dropped as the device is busy processing other processes [MS10]. 


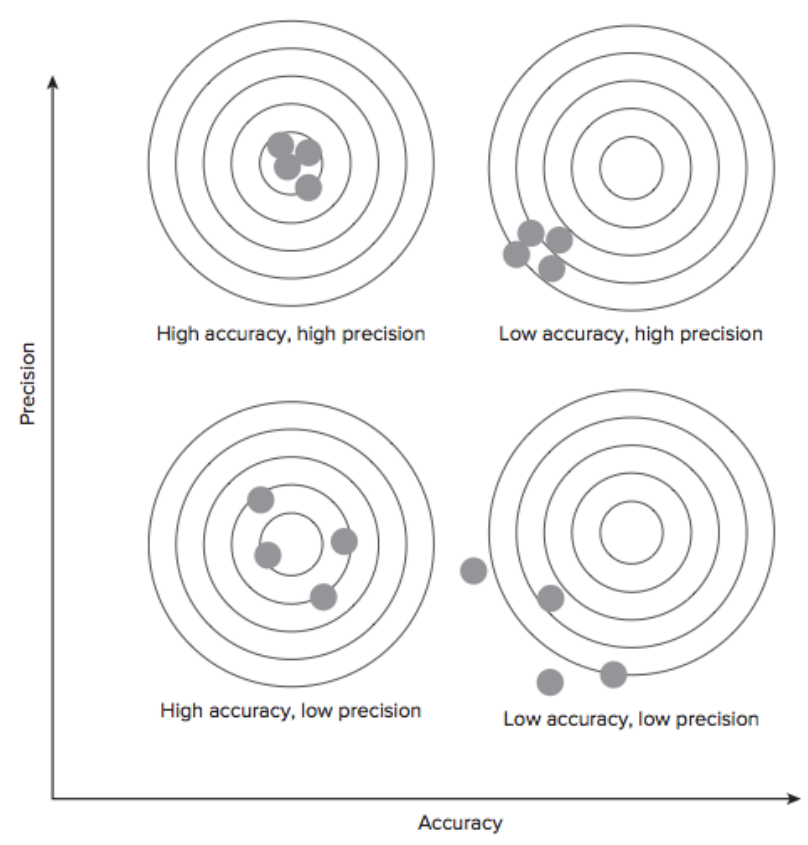

Figure 3.2: Accuracy and Precision[MS10].

\section{Accuracy and Precision}

Accuracy and precision are two essential concepts regarding the sensor analysis. High accuracy means that the values measured by the sensor are close to the real value, while high precision means that all the values are close to each other, but does not ensure that the values are close to the real value. In Figure 3.2 it is possible to analyse the differences between accuracy and precision [MS10].

\section{Filters}

Some of the existing filter techniques uses an approach called low-pass filtering that filters out high-frequency noise. The weighted smoothing, the simple moving average and the simple moving median are some of the existing low-pass filtering techniques.

High-pass filtering is another technique but in this case the main objective is to emphasizes the higher-frequency instead of removing it. The easiest way of applying a high-pass filter is to apply a low-pass filter to the data and then subtract the original sensor data.

When the objective is to emphasize only a certain frequency the best approach is to use a bandpass filter [MS10].

There are also some techniques that are more complex to implement and understand like Kalman filters that require previous knowledge about the data source. Kalman filters are very flexible and have numerous applications in technology as it can be used to smooth high-frequency noise, isolate part of the signal, among others [MS10]. 


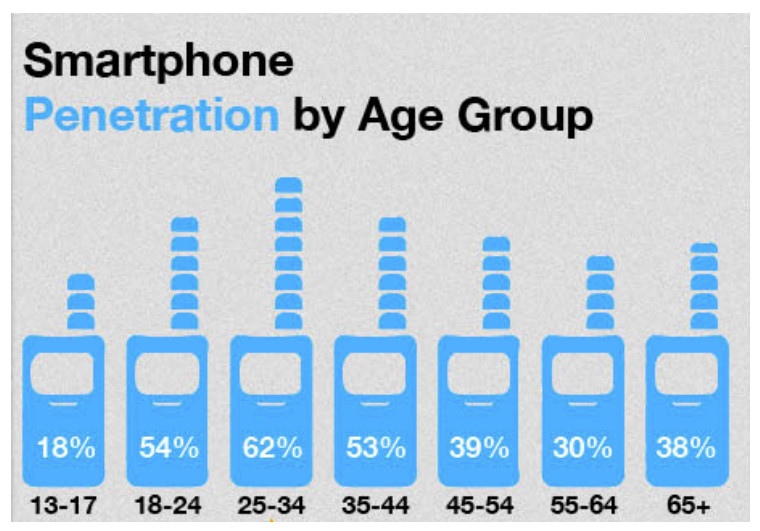

Figure 3.3: Smartphone penetration by age group[GG12].

\subsection{Smartphones and Elderly}

We live in the generation of computers and smartphones, and they are constantly present in daily life. For the younger population these technologies are extremely easy to use and interact, but for an elderly generation born in a period when personal computers did not exist they are complicated. Therefore it is expected that they have less familiarity with information technology and therefore more difficulties in using them [BCCP12].

Ageing is also associated with a decline of the functional abilities, and consequently it becomes even harder to interact with a smartphone [SS10]. Therefore it is necessary to design interfaces that are aimed to this age range. These interfaces must be functional, simple and above all intuitive and easy to use [JGG04].

Despite these difficulties, the number of older persons using a smartphone is increasing at high speed, and in 2012 the smartphone had a percentage rate of 38\% over 65 years old, and a rate of $30 \%$ between the 55 and 64 years-old, as shown in Figure 3.3. These increasing rates are essential to the success of smartphone-based applications designed for the older population [GG12].

\subsection{Existing Solutions}

There are already some technological solutions in the market that try to reduce the risk of falling among elderly people. Although they are somehow similar they do not achieve all of the requirements needed to correctly reduce the fall risks in older population, as they are too expensive or as they require specific equipments. Additionally there is another set of applications which the principal object is to prevent falls or even fall risk assessment, that in some situation may prevent falls as a secondary effect. In the next subsections is done an overview of some existing solutions.

\subsubsection{SmartSenior's Interactive Trainer}

SmartSenior's Interactive Trainer is a interactive system for a home based fall prevention training for elderly people. It is presented as a solution that takes into account that exercises designed to 


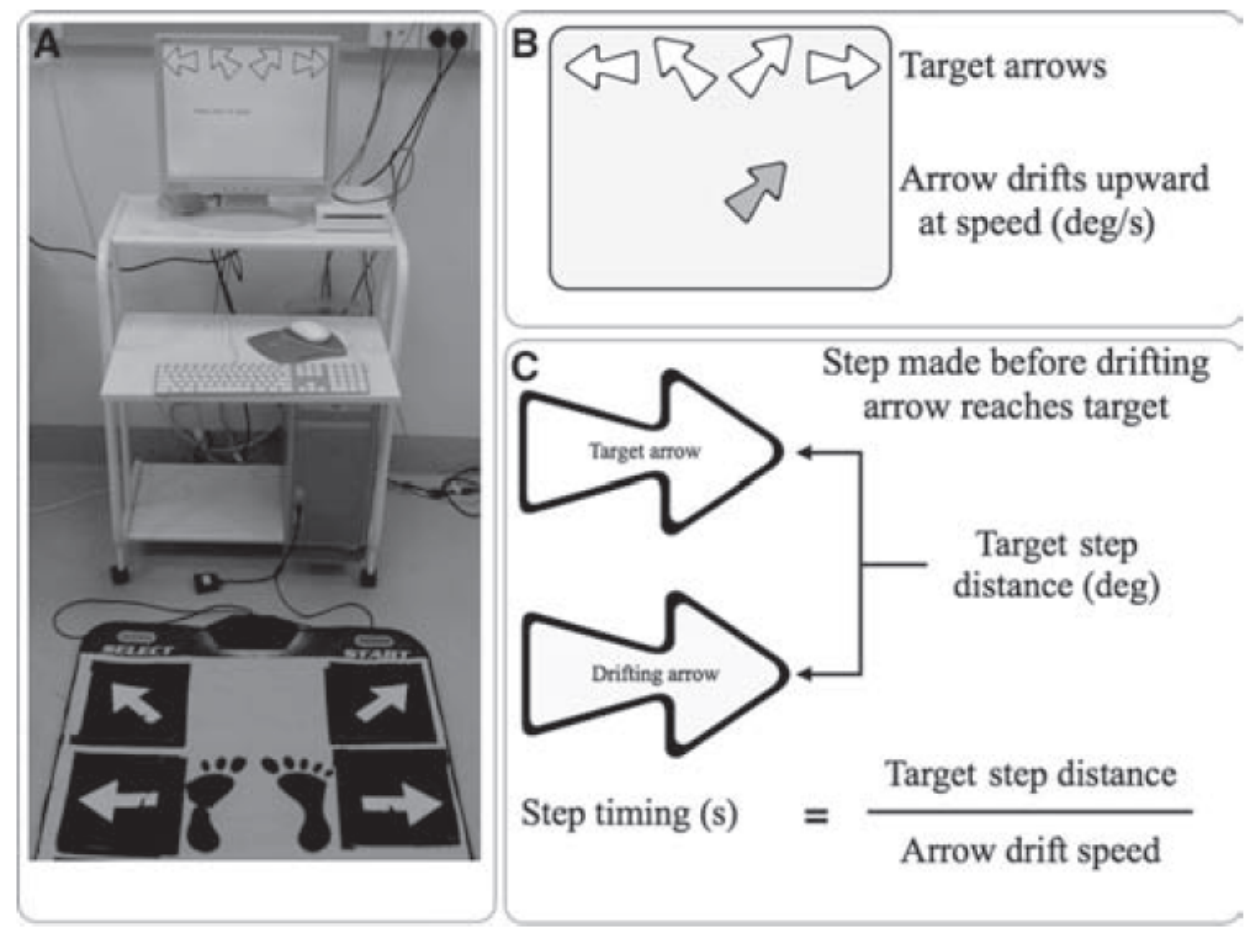

Figure 3.4: Dance Dance Revolution.

improve balance and strength should be done continuously to avoid a drop back of the capabilities acquired.

This system is quite complex requiring a computer, ambient sensors like camera and microphone, as well as an inertial sensor build into a belt. This inertial sensor consists in a 3D accelerometer that provides information about the user movements.

Each patient training program is actualized in the beginning of the session, and proper feedback is given through a dialogue system. After the training, every data collected is stored and used for further analyses.

SmartSenior's Interactive Trainer also allows the therapist to interaction with the user using an audio and video communication system. This interaction is important to solve arising problems or act just like a normal scheduled meeting, but instead of being a face-to-face meeting, it avoids the normal costs of transportation $\left[\mathrm{JKK}^{+} 12\right]$.

\subsubsection{Dance Dance Revolution}

Dance Dance Revolution is based on the game with the same name, but with specific tweaks to reduce fall risk by improving the user balance. The main difference between this solution and console games, is being able to send feedback to the doctors. It is a good solution that allows the user to practice at home or institution but the user can only improve his balance not being able to improve others characteristics that may lead to fall. 

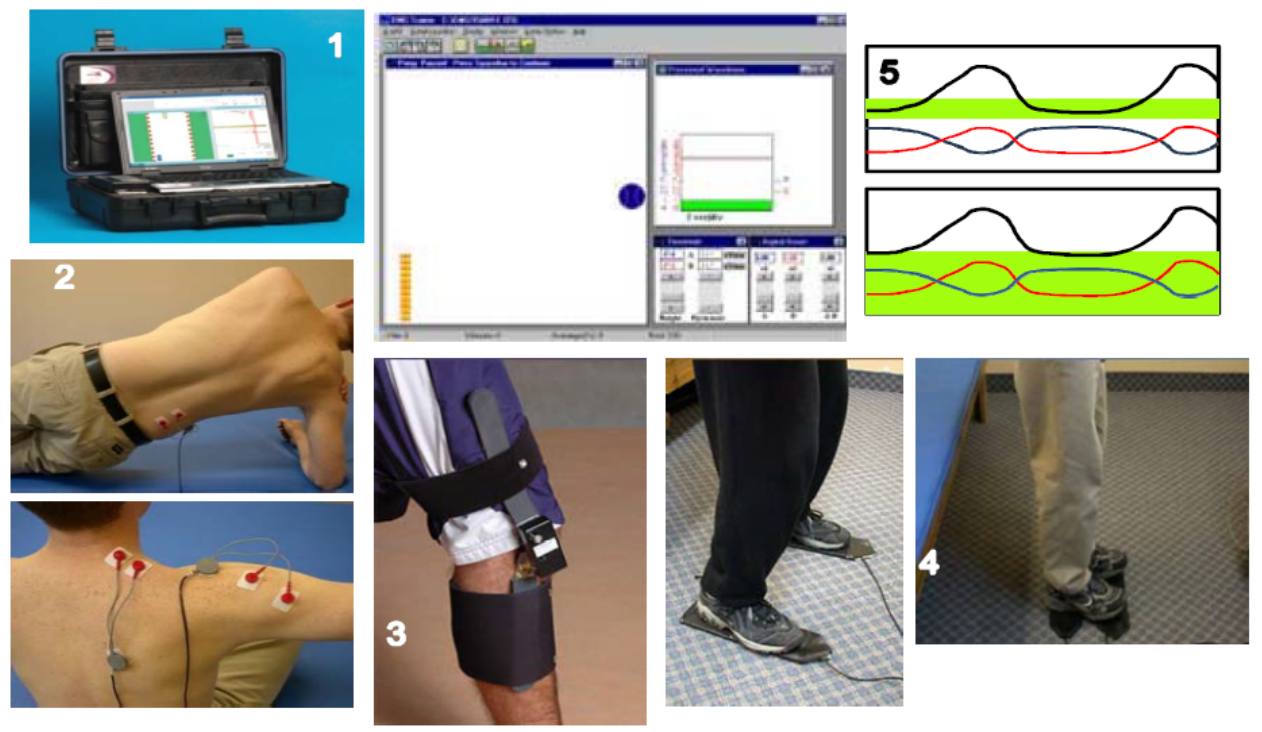

Figure 3.5: NeuroGym Training System.

DDR use a modified USB DRR mat with four step-sensitive target panels and it is connected to a computer running a customised version of the DRR game. The game have four target arrows that represents the movements that user need to perform. During the game are measured some metrics like average step timing, percentage of missed targets or percentage of correctly made steps (Figure 3.4). The system provides a low-cost technique that allow older adults to improve their balance at home avoiding the normal costs of transportation [ $\left.\mathrm{SSS}^{+} 11\right]$.

\subsubsection{NeuroGym}

NeuroGym is a game based in biofeedback training that uses augmented sensory feedback to control the action in the game. In order to obtain the sensory feedback, NeuroGym use pressure sensors together with EMG sensors (Figure 3.5).

This solution improves the muscle activation and gait pattern, while improving functional balance. Despite the results of this solution it is very expensive and requires specific knowledge to operate the equipment [HLN09].

\subsubsection{Dance Don't Fall}

Dance Don't Fall is a game-like application whose the main objective is to monitor the risk of falling as well as reduce the risk of falling through exercises, more specifically, through the use of dance movements. This application just requires a simple Android smartphone and therefore it is extremely portable and the user can practice their dances everywhere he wants. Fall risk assessment is based on movement analysis while the person is dancing. If there is a suspect of increased risk exists based on those movements, a questionnaire is used to assess other risks for falling [Por13]. 

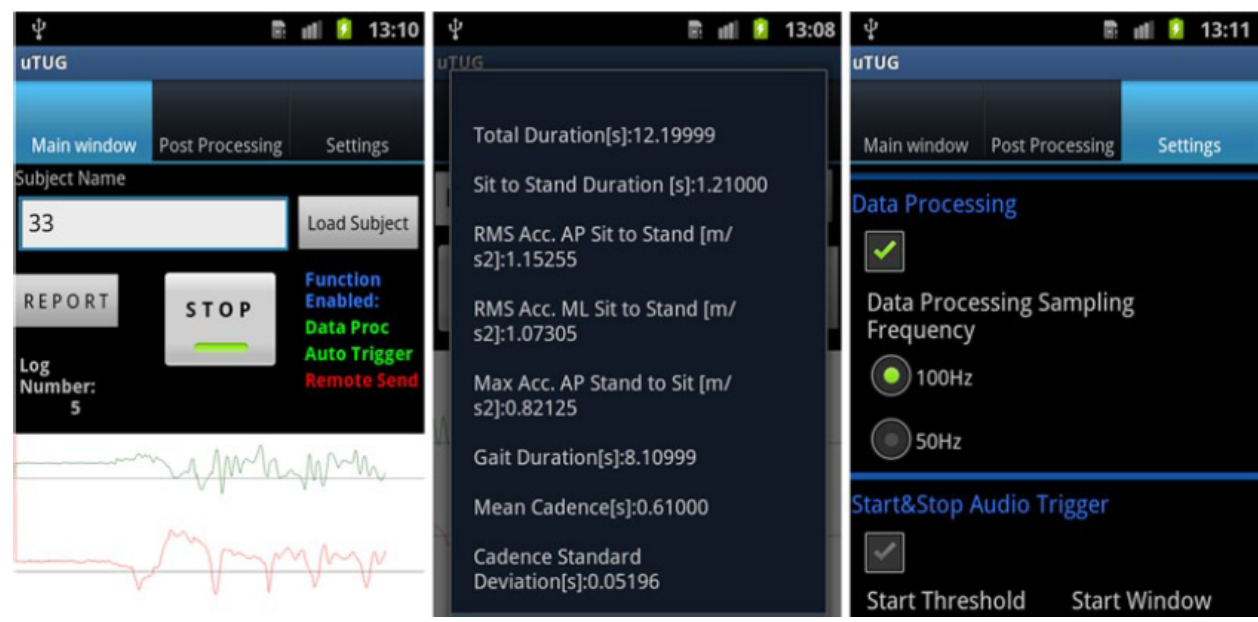

Figure 3.6: uTug application user interface.

The fall prevention technique used in this application do not include specific movements designed to reduce fall risk, but is based on the general assumption that being inactive constitutes an important risk for falling. Therefore, a person using the system may be more active, which may reduce the risk of falling.

\subsubsection{Portable Acceleration Monitor Device}

This solution for fall prevention consists in using a portable acceleration device that have a microcomputer associated with an 3-axis acceleration sensor.

The authors of this solution propose the analysis of the acceleration of the center of gravity of body during sit-to-walk motion. The step width and length as well as the displacement width of the extrapolated center of mass are related with the decrease of physical strength and with the fear of fall. Processing the information from this tests may be useful as a screening test for fall prevention [SAOM12].

\subsection{6 uTug}

The main focus of this solution is not fall prevention, but it is one standalone application instrumenting clinical functional tests as the time up and go. The uTug can be seen as a tool for fast screening and fast assessment in order to assess the patient's mobility and therefore identify possible fall risk factors (Figure 3.6).

This solution as the advantage of being capable of having algorithms capable of activity recognition. One of those recognized activities is the sit to stand, that is also used as a fall prevention exercise $\left[\mathrm{MTS}^{+} 12\right]$. 
Existing Technological Solutions

Table 3.1: Solutions comparative.

\begin{tabular}{|c|l|l|}
\hline Solution & Positive Aspects & Negative Aspects \\
\hline \hline DDT & $\begin{array}{l}\text { Portable allowing the user to use it ev- } \\
\text { erywhere }\end{array}$ & $\begin{array}{l}\text { The lack of movements designed to re- } \\
\text { duce fall risk }\end{array}$ \\
\hline DDR & Home-based and low-cost solution & Only improves balance \\
\hline EMG & $\begin{array}{l}\text { Improves muscles activation, balance } \\
\text { and gait pattern }\end{array}$ & $\begin{array}{l}\text { Very expensive and requires specific } \\
\text { knowledge }\end{array}$ \\
\hline PAMD & Portable and low-cost & $\begin{array}{l}\text { Only useful as a screening test for fall } \\
\text { prevention }\end{array}$ \\
\hline SSIT & $\begin{array}{l}\text { Improves balance and strengt with } \\
\text { medical monitoring }\end{array}$ & $\begin{array}{l}\text { Quite complex system } \\
\text { the sit to stand exercise }\end{array}$ \\
\hline uTug & $\begin{array}{l}\text { Activity recognition algorithms, like } \\
\text { It is all screening solution }\end{array}$ \\
\hline
\end{tabular}

\subsection{Summary and Conclusions}

Existing solutions show that exist a long path to travel in order to deliver a portable, simple and low-cost solution to perform fall prevention exercises. The idea of having a portable device is to allow the person to perform a recommend set of exercises independently of his location.

From the solutions analysed is possible to say that some of them already allows the elderly to perform the fall prevention exercises at home and with medical advice, but they restrict their use to a specific area. On the next table (Table 3.1) is possible to compare the most relevant aspects of each solution analysed. 
Existing Technological Solutions 


\title{
Chapter 4
}

\section{The Smartphone-Based Solution}

\begin{abstract}
A prototype was built taking into account a set of requirements. The prototype construction involves a few distinct phases. The first one explores the best position to attach the smartphone to the user. The second phase, more exploratory, involves recording sensor data, analyse the data gathered and compare the values provided by the different positions of the smartphone. The last one is more technical, involving the design of the algorithms to process the movements and provide the correct feedback to the users.
\end{abstract}

\subsection{Architecture}

The actual solution of this project has three principal components, the hardware communication layer, the data processing layer and the interface layer, and an additional pre-processing layer (Figure 4.1).

The hardware communication layer is responsible for the direct interaction with the Android API. In this layer it is defined which sensors are going to be used and their refresh rates. Moreover, data from sensors is collected, processed by the data processing layer, saved and finally the access to the sensors is closed.

The second layer is the data processing layer. It is the core of the application responsible for analyse and process the data, and it is detailed in Subsection 4.1.1.

In addition to these two components, the interface layer is responsible for the feedback of each exercise, showing to the user the metrics associated with each exercise. This layer is also responsible for processing the user input regarding the choice of exercises.

Finally, the pre-processing layer is used when is necessary to apply filters to the raw data before being processed by the data processing layer. In addition, the filter application, this layer is responsible to apply some sensor processing techniques like adding a safe value to the readings in order to be always positive or squaring the values read by the sensors. 
The Smartphone-Based Solution

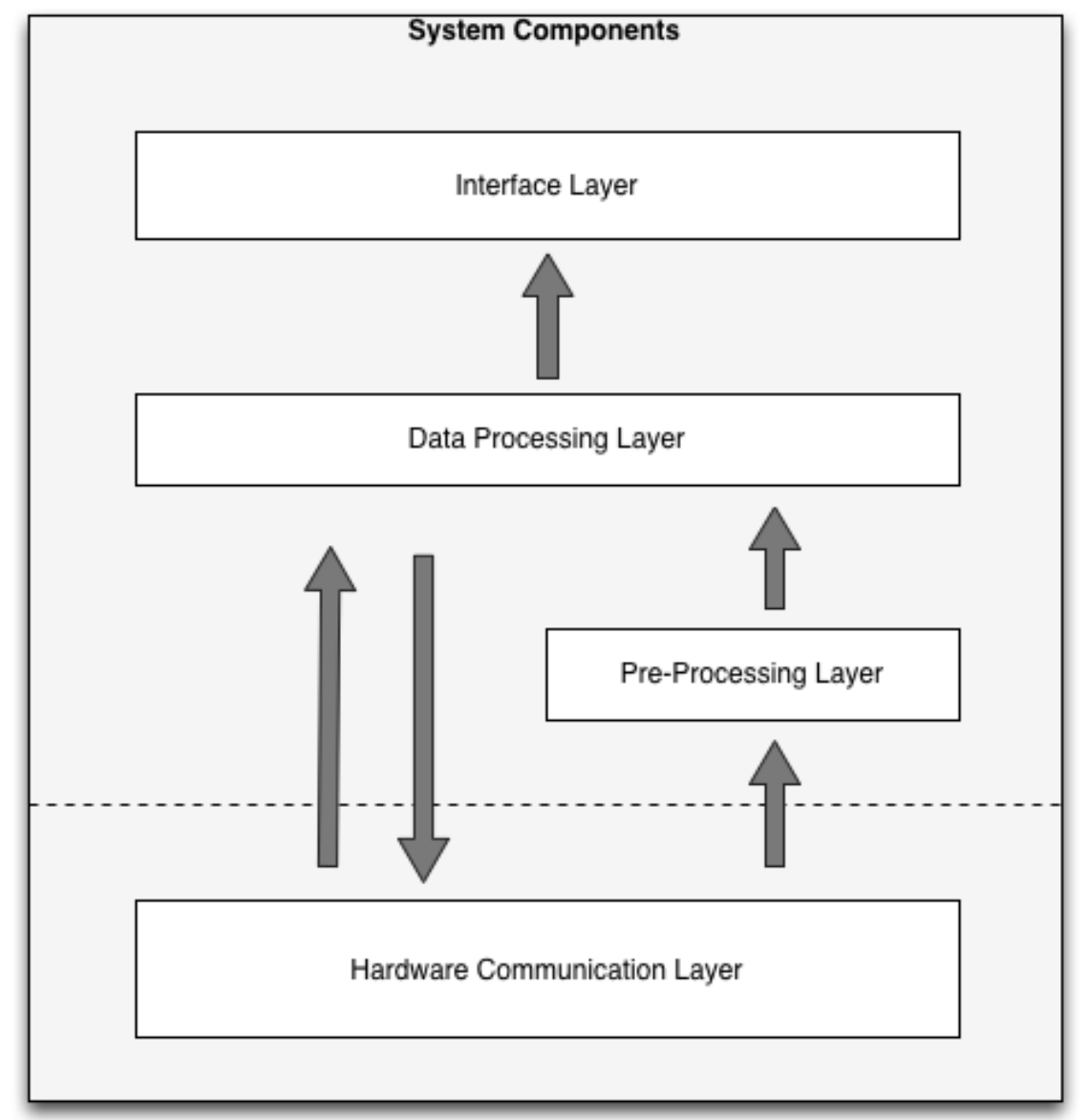

Figure 4.1: System Architecture. 


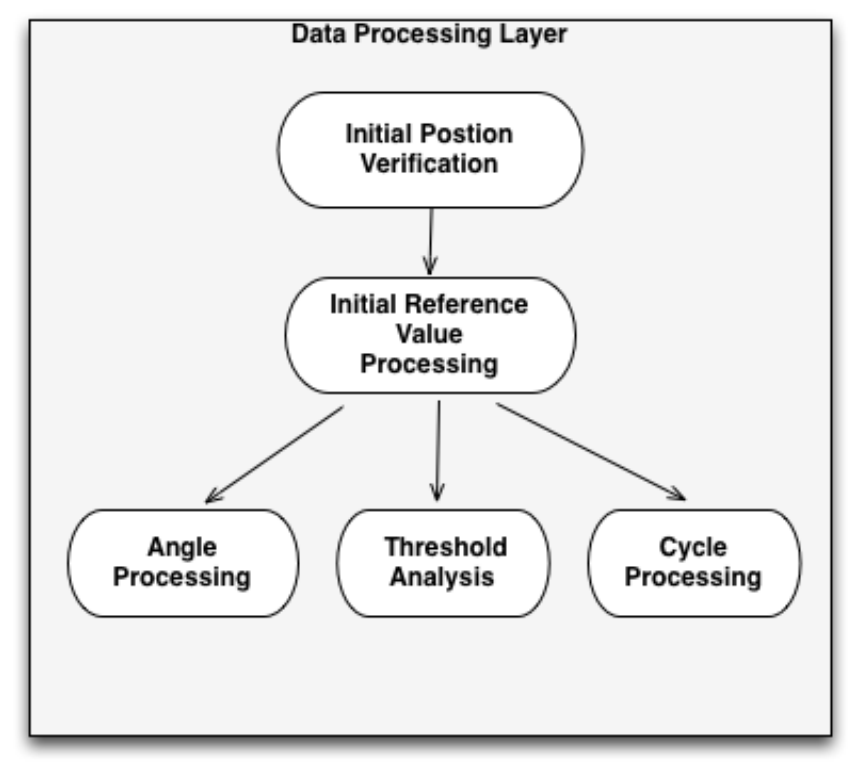

Figure 4.2: Data processing layer components.

\subsubsection{Data processing layer}

With five main components (Figure 4.2), the data processing layer is the kernel of this project. One of them is responsible for the angle calculation, between the world vertical and an axis of the smartphone. Another one is the threshold analysis that is a generic function that receives raw data or already pre-processed data and processes it according to the received thresholds and if that threshold is likely to be found in a local maximum or minimum.

For a correct signal processing based in thresholds it is required to process and validate the initial position of the smartphone and after that it is necessary to calculate a reference value for each person. This value is extremely important for exercises that may suffer from the influences of the chair size and the length of the user's legs.

Finally, it also has a function for full cycle processing used when it is important to collect a full variation from a local maximum to local minimum regardless thresholds.

\subsection{Smartphone Positioning}

For the success of this approach it was necessary to define the best position to attach the smartphone to the user during the execution of exercises. This attachment is made using a comfortable armband as shown in Figure 4.4a.

The chosen position should have into account the user's comfort and the quality of the sensor's readings. Based on the exercises characteristics and the size of a smartphone, a few possible positions were found, namely, the waist, arms, legs or hands. 

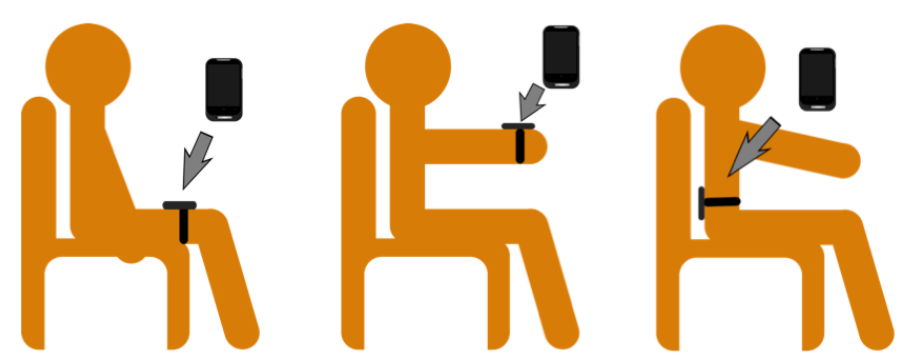

Figure 4.3: Possible Smartphone Locations.

These four locations may create an unpleasant utilization for the user due to the necessity of being constantly changing the smartphone position. Bearing in mind that it is essential for the success of the project to have an extremely easy set up of each exercise, it was necessary to reduce to the minimum the number of possible locations.

The first position to be excluded was the hands as it is a more volatile position, in which the user may accidentally drop the smartphone. The rest of the possible positions (Figure 4.3) are equally comfortable and reliable for movement detection, but three positions are still too much to build a pleasing user application.

As the fall prevention program chosen to support this application is mainly focused on arms and legs movements, they could be divided into two groups. Starting with four exercises that have their focus on the legs it becomes possible to define the first position for the smartphone, on the user thigh, just above the knee (Figure 4.4c). The rest of the exercises haver their focus on the arms, and therefore with the smartphone on the first position it is not possible to detect and evaluate the movements performed by the user.

Being necessary to find a new position for these exercises the choice felt over the arm, more specifically on the wrist (Figure 4.4b). With this division it was possible to have only two locations for the smartphone, reducing the user interaction and increasing the usability of the system. In both positions the smartphone is comfortably strapped to the user with an armband with a slight extension in order to be strapped to the thigh.

\subsection{Prototype}

So far, several concerns were presented that need to be taken into account so that the platform requirements are fulfilled. The platform must incorporate several sensors capable of detecting movement, acceleration and relative position. Nevertheless is must be affordable to the masses and have an easy and interactive interface. Having these in mind an Android-based prototype, based on a "Samsung Galaxy Nexus", was built.

This device has a very complete set of native sensors as well as sensor fusion techniques that are available as a sensor through Android API. In this prototype it was used the accelerometer, the gravity, the rotation vector and the linear acceleration sensors. The Table 4.1 summarizes the information relative to the specifications of the inertial sensors used. 


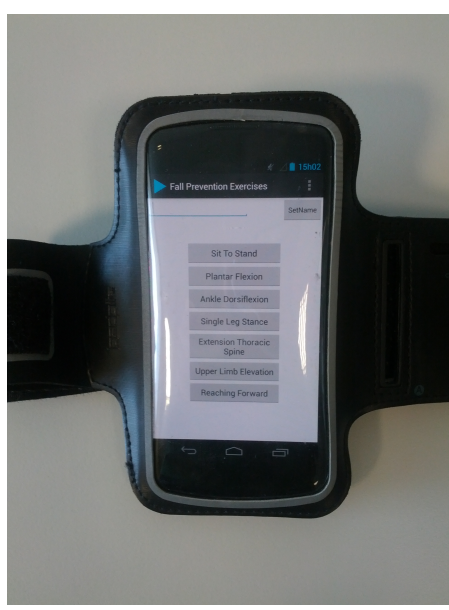

(a) Armband

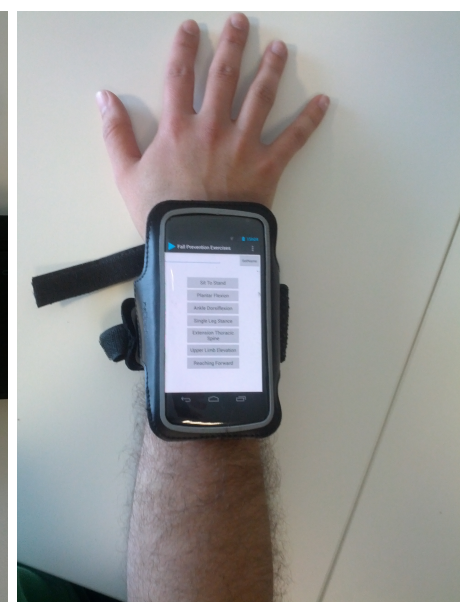

(b) Wrist Position

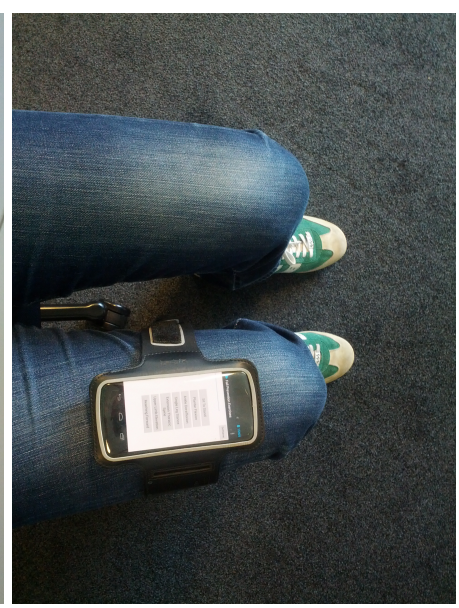

(c) Thigh Position

Figure 4.4: Smartphone Final Locations.

\section{Interface}

The prototype developed has a very simple interface, since it main focus was to detect, process and provide feedback regarding the users' movements. Therefore in the initial screen, besides the exercise selection, it is possible to define the name of the user that is performing the exercise in order to associate the saved results with that user as shown in Figure 4.5a.

For each individual exercise a script is provided to help the user perform in a correct way the exercise (Figure 4.5b). An evaluation of the exercise is provided by means of specific metrics calculated by the developed algorithms. In Figure $4.5 \mathrm{c}$ it is possible to see an example of a feedback for the reaching forward exercise.

\subsection{Movement Analysis}

In order to provide correct feedback to the user was necessary to develop algorithms capable of evaluating in real-time the exercise execution. This real-time analyses were accomplished using thresholds during the exercise execution and comparing the sensor's readings with the threshold value in order to detect the current position of the smartphone. Position that may vary in line with the movement.

With the objective of obtaining initial thresholds to start developing the final solution it was necessary to perform an initial evaluation of the movements as described in Subsection 4.4.1.

After this initial analysis and during the algorithms development was necessary to implement a low-pass filter (Subsection 4.4.3) capable of smoothing the readings and producing clear readings of the exercises performance.

Additionally the metrics necessary to correct evaluate some of the exercises required the creation of an algorithm capable of measuring the angle performed between the Y-axis of the smartphone and the gravity (the world vertical), as shown in Subsection 4.4.2. 
The Smartphone-Based Solution

Table 4.1: Details of the used sensors.

\begin{tabular}{cccccc}
\hline Sensor & Name & Vendor & Power & Maximum Range & Resolution \\
\hline \hline Acc & MPL Accelerometer & Invensense & $0,139 \mathrm{~mA}$ & $10,6133 \mathrm{~m} / \mathrm{s}^{2}$ & $0,0383 \mathrm{~m} / \mathrm{s}^{2}$ \\
Grav & MPL Gravity & Invensense & $10,239 \mathrm{~mA}$ & $19,6133 \mathrm{~m} / \mathrm{s}^{2}$ & $0,0383 \mathrm{~m} / \mathrm{s}^{2}$ \\
Lacc & Linear Acceleration Sensor & Google Inc. & $10,239 \mathrm{~mA}$ & $19,6133 \mathrm{~m} / \mathrm{s}^{2}$ & $0,0383 \mathrm{~m} / \mathrm{s}^{2}$ \\
RotVector & MPL Rotation Vector & Invensense & $10,239 \mathrm{~mA}$ & 1,0 & 0,00001 \\
\hline
\end{tabular}

\subsubsection{Initial Analysis}

In this phase it was necessary to find a way to collect and analyse the data gathered from the inertial sensors. To record this data, a simple Android application was built. This application had access to the data read by the sensors and saved the information in an external file. Additionally the signal acquisition could be performed using different sampling rates. In Android, it is possible to define four different default rates: the Fastest, the Game, the UI and, finally, the Normal [MS10].

After recording the exercises with Android it was necessary to process that information. A program in Python was used to read files and process the recorded signals. To obtain a visual analysis of the results it was used a Python 2D plotting library, the matplotlib. With this approach it was possible to build a plot for each sensor, exercise and experimental positioning of the smartphone. It was also necessary to define the most appropriated axis or axes to process data. Looking to Figure 4.6 it is possible to see the clear variation that is produced in each axis of the accelerometer during the execution of the upper limb exercise. In this movement a variation is produced by the gravity on the Y-axis that goes from near $-10 \mathrm{~m} / \mathrm{s}^{2}$ at the initial position to $10 \mathrm{~m} / \mathrm{s}^{2}$ when the exercise position is reached. At this stage, the arms are forced to stay in this position with small forcing movements, which are more easily readable on the Z-axis of the linear acceleration sensor.

\subsubsection{Angle Between the Vertical and Smartphone Axis}

Using the gravity sensor provided by the Android API it is possible to calculate the angle between the vertical (of the world) and one of the smartphone's axes. This can be achieved with the dot product between two vectors.

The vertical of the world corresponds to the gravity vector, and its value can be read by the smartphone gravity sensor. As shown in Figure 4.7, the gravity vector has always the same direction regardless the smartphone position. Therefore it is possible to measure the angle performed by the gravity sensor with a chosen axis, in this case the Y-axis.

On the Equation 4.4.2, the vector $a$ corresponds to the gravity vector and it can be obtained by reading the three axes values of the smartphone gravity sensor, such that:

$$
a=[\text { gravity }[x], \text { gravity }[y], \text { gravity }[z]]
$$

While the value of vector $b$ is given by reading the values on the Y-axis, such that:

$$
b=[0, \text { gravity }[y], 0]
$$




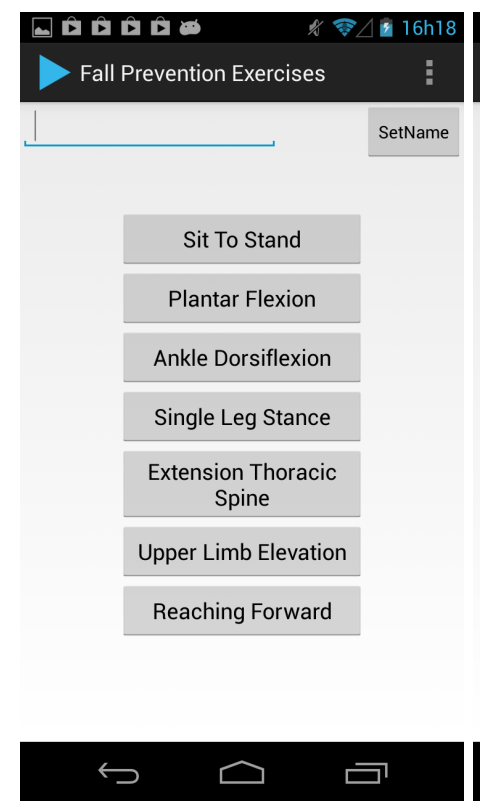

(a) Initial Screen

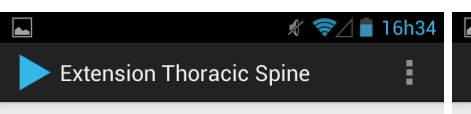

Baixe o braço, rode a palma da mão para a frente $e$ puxe o braço para trás. Comece o movimento.

\section{-}

Reaching Forward

* Tempo no $1^{\circ}$ levantamento: 3.09 s, Ângulo Máximo: $109.97^{\circ}$ Tempo no $2^{\circ}$ levantamento: 3.58s, Ângulo Máximo: $109.97^{\circ}$

Tempo no $3^{\circ}$ levantamento: 1.39s, Ângulo Máximo: 126.09

\section{$\hookleftarrow \curvearrowleft \square$}

(b) Guiding Screen

\section{(c) Results Screen}

Figure 4.5: Solution Interfaces.

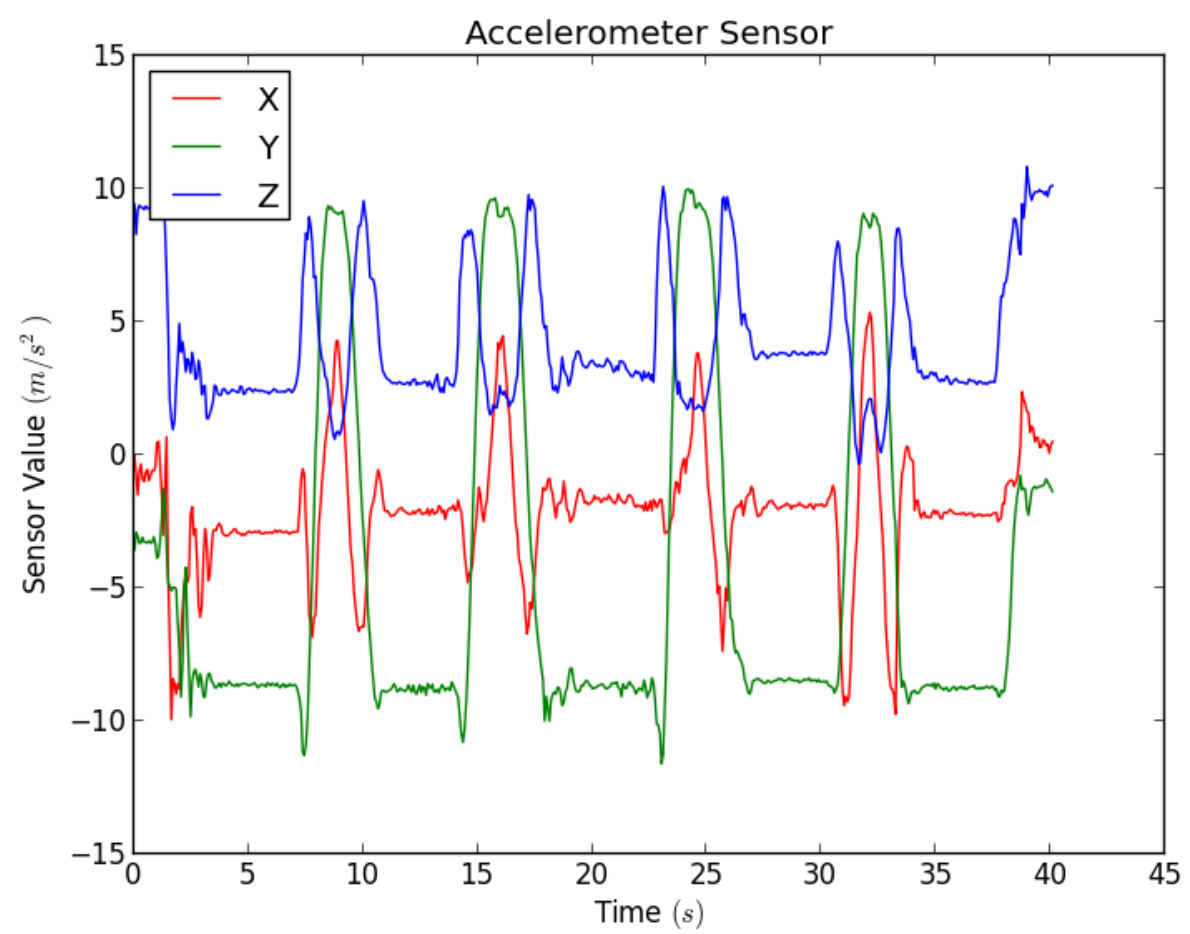

Figure 4.6: Upper Limb Elevation recorded with accelerometer. 


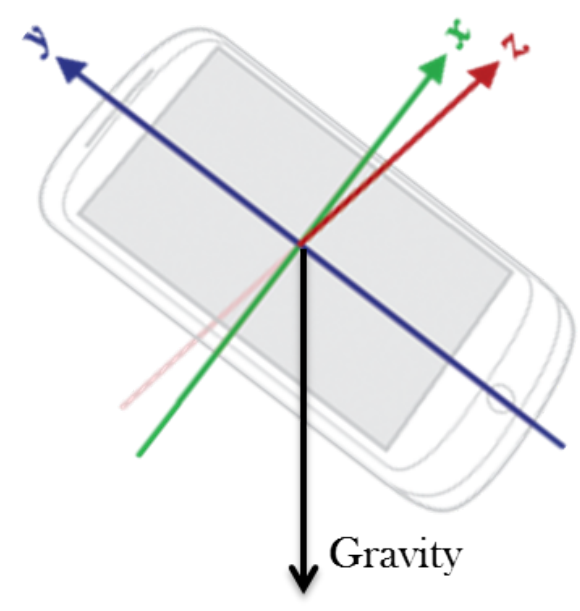

Figure 4.7: Android axes and gravity vector.

$$
a . b=|a| *|b| * \cos (\theta)
$$

Finally the value of the angle performed between these two vectors is given by the value of $\theta$.

\subsubsection{Low-Pass Filter}

Filters are a method used to handle with encountered errors on sensors' readings. For this project it was necessary to find an adequate method to smooth those values. One possible method is the application of a low-pass filter that enables to remove any high-frequency noise from the signal.

From the low-pass filter methods available, it was chosen the weighted smoothing, becoming possible to obtain a more uniform set of readings. This very common method consists in weighting the newest value against the old mean [MS10], such that:

$$
\text { NewValue }=\text { LastValue }+x_{i} * a-\text { LastValue } * a
$$

Where the $x_{i}$ is the value read from the sensor, and $a$ is the smoothing value. The smoothing value may vary between 0 and 1 , where the $a=0$ produces no effect on the data, while with $a=1$ the mean is totally controlled by the newest values. In this case the value of $a$ is 0.1 , which is a decent choice for a smooth plot. 


\section{Chapter 5}

\section{Exercise Processing}

This last step is probably the most important but it was impossible to accomplish it without the previous two steps. At this point the smartphone position is defined for each exercise, as well as the metrics that should be collect and processed for each exercise. Therefore it was necessary to start creating algorithms for real-time processing and analysis as well as the necessary sensor rates values and which sensor is going to be used for each separated exercise. Moreover it is necessary to have in mind that this is a mobile device and it is powered by a battery, therefore it is necessary to minimize the battery usage.

One of the metrics used to evaluate the exercises was the execution time. In order to obtain a precise time it was used the timestamp of the event provided by the Android API, which returns the time at which the event happened in nanoseconds, in combination with the system nano time that is used to measure the elapsed time between the timestamps [Inc].

\subsection{Extension of the Thoracic Spine}

On this exercise the patient must be sitting on a chair and with his/her arms parallel to the body (Figure 5.2a). The exercise starts by rotating the palm of the hand to the front and push both arms to the back, performing an isometric contraction as shown in Figure 5.2b.

In order to perform a correct evaluation of the movement is was necessary to use a combination of sensors provided by the Android API, the accelerometer, the gravity and the linear acceleration sensors.

The accelerometer is used to verify the initial position of the smartphone, in this case is possible to evaluate if the smartphone is perpendicular to the ground as well as the hand rotation that sets the starting point of the exercise. At this moment, a sound is produced so that the user can have the perception that he/she had started the exercise. In Figure 5.1a is clear the variation produced on the accelerometer when performing 5 times the exercise. 


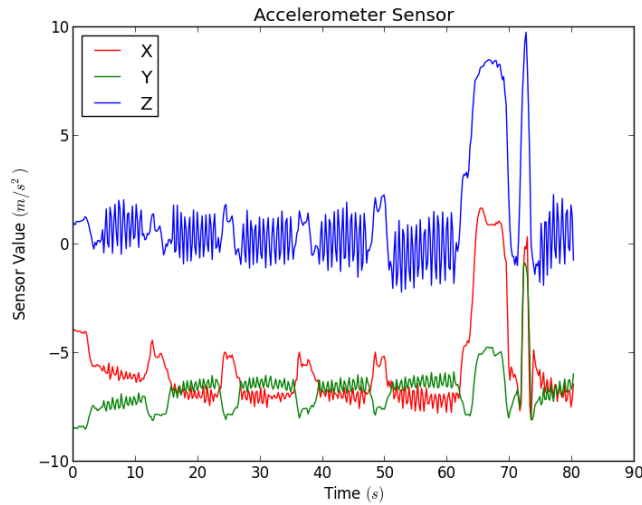

(a) Accelerometer Sensor

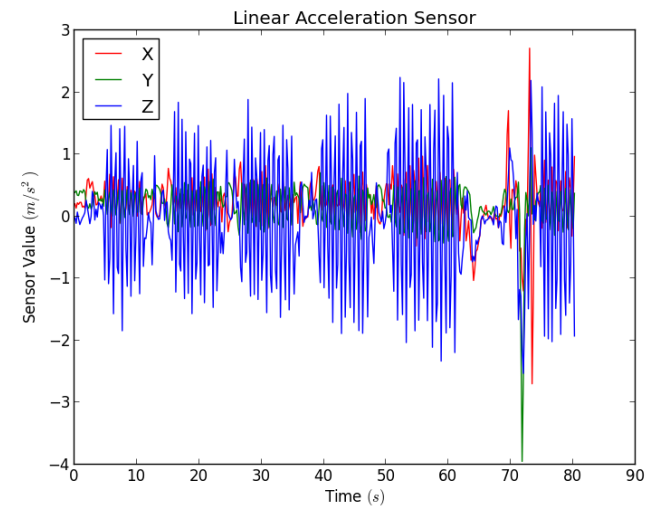

(b) Linear Acceleration Sensor

Figure 5.1: Extension of Thoracic Spine recorded with accelerometer and linear acceleration sensors.

Besides the duration of each execution it is also evaluated the number of times in which the user forced the position, to achieve this it was used the linear acceleration sensor. A forcing is considered when the signal from the linear acceleration has a maximum followed by a minimum; these two values represent a full movement when the user is forcing the position. In this case the linear acceleration was used, as the main objective was to detect the movements performed by the user and without the influence of gravity (Figure 5.1b).

Finally the gravity sensor is used to calculate the angle of the smartphone with the vertical. For each repetition the maximum angle reached by the arm during the exercise is calculated.

\subsection{Upper Limb Elevation}

As the extension of the thoracic spine (Section 5.1), the upper limb elevation must be performed sitting on a chair with arms parallel to the body (Figure 5.2a) and elevate them above the head (Figure 5.2c).

In this case it was necessary to use the linear acceleration sensor, the gravity sensor and the rotation vector sensor to detect the smartphone position. With the combination of the three sensors it is possible to understand if the screen is rotated to the right side, if the smartphone is perpendicular to the ground and most importantly if it was subjected to an acceleration from the bottom to the top. In Figure 5.3a is perceptible when the smartphone is perpendicular to the ground or not, additionally in Figure 5.3b it is possible to see the screen rotation despite the high variations on the Z-axis.

After evaluating the values from these sensors a sound is produced and the application starts to count the exercise duration. During the exercise the data provided by the linear acceleration sensor is being used to process the number of times the user forces the position exactly as in the extension of the thoracic spine (Section 5.1). 


\section{Exercise Processing}

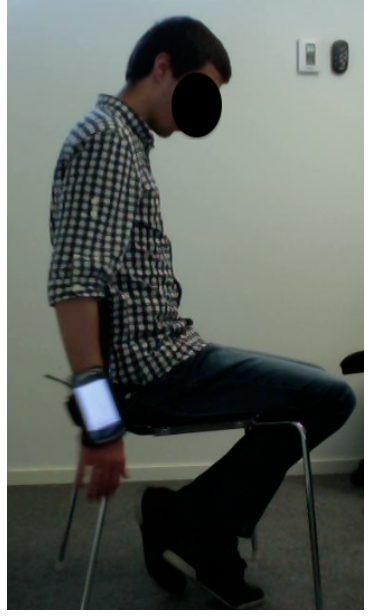

(a) Initial Position

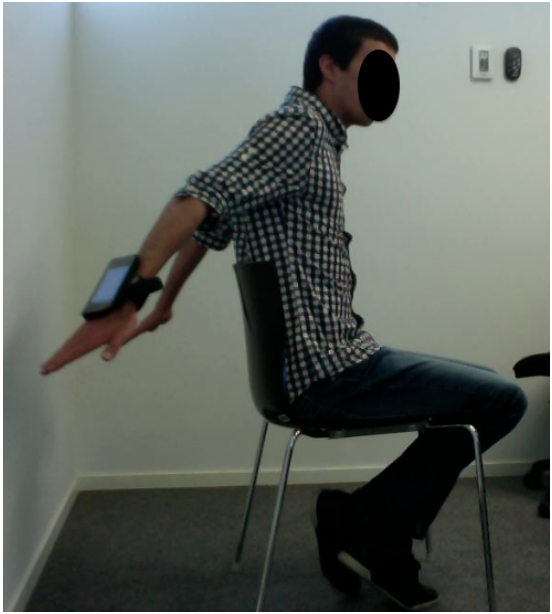

(b) Extension of Thoracic Spine

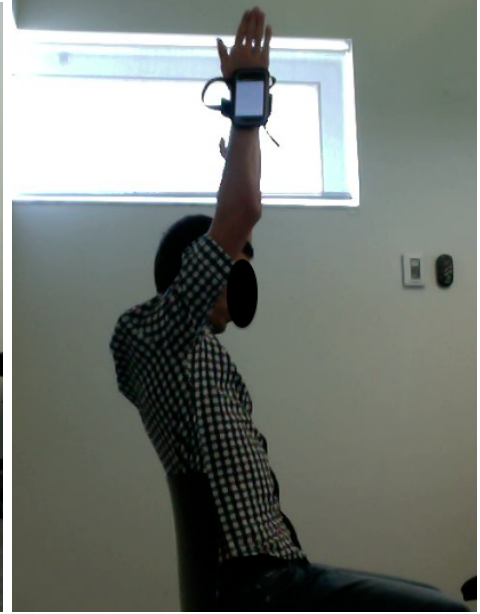

(c) Upper Limb Elevation

Figure 5.2: Exercise execution illustration.

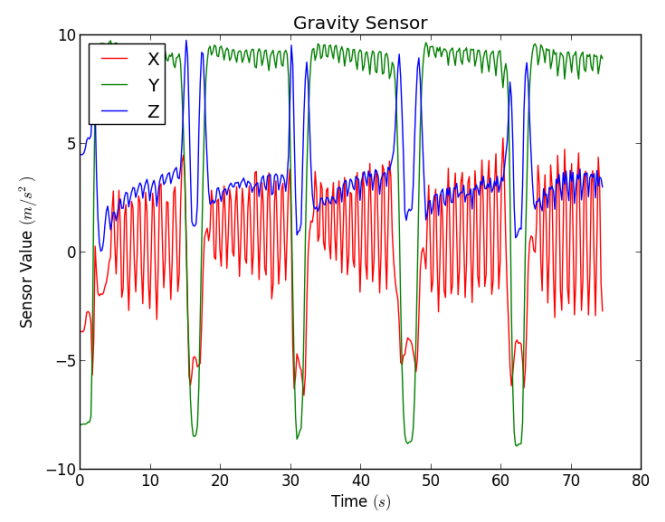

(a) Gravity Sensor

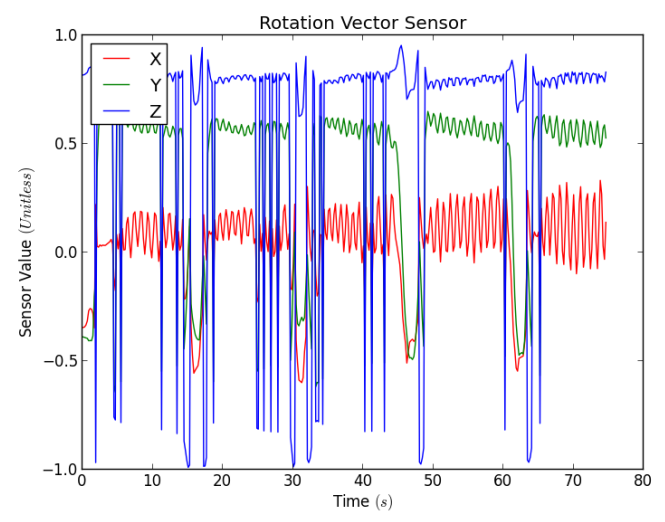

(b) Rotation Vector Sensor

Figure 5.3: Upper Limb Elevation recorded with gravity and rotation vector sensors. 


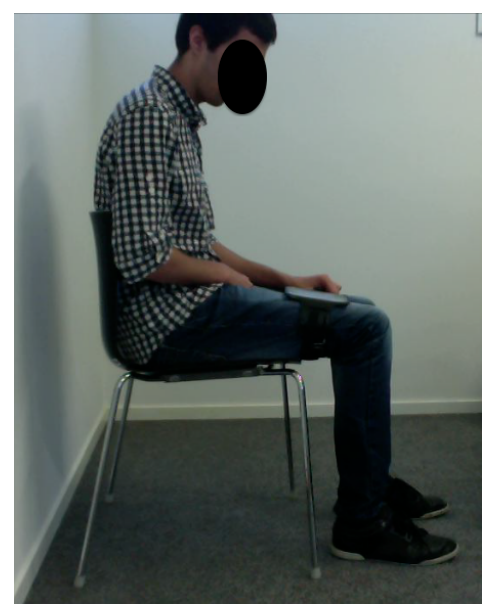

(a) Initial Position

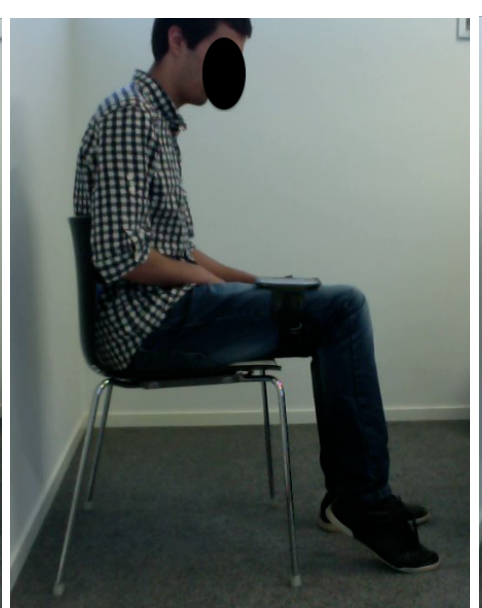

(b) Plantar Flexion

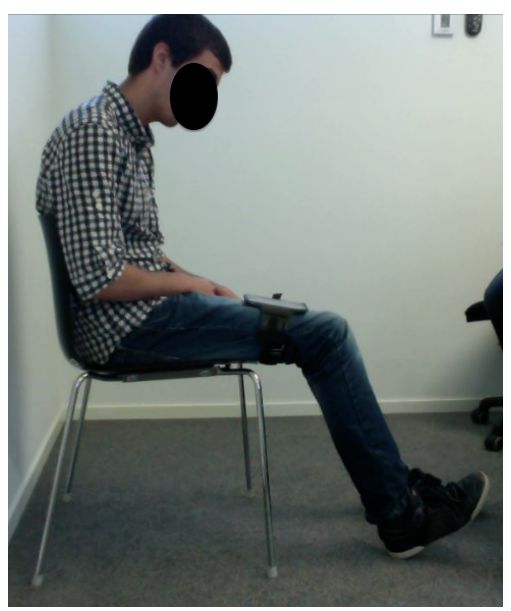

(c) Ankle Dorsiflexion

Figure 5.4: Plantar flexion and Ankle Dorsiflexion execution illustration.

\subsection{Plantar Flexion and Ankle Dorsiflexion}

These two exercises are quite simple to perform but at the same time are difficult to evaluate, mainly due to the chosen position of the smartphone. In this exercise the user is sitting on a chair and with the legs performing an angle of $90^{\circ}$ as shown in Figure 5.4a. On the plantar flexion exercise the user raises his heel and hold the position (Figure 5.4b), while on the ankle dorsiflexion the user raises his toes (Figure 5.4c).

The difficulties of evaluation are caused by the small variations that this movements produces on the thigh, therefore it was necessary to find methods to workaround this problem. The first approach was to change the sensor rate to the Fastest, as the delay of the normal rate is too big to detect small variations. The original signal in Figure 5.5a shows that only the Y-axis is affected by the exercise execution but this variation is too small and the values are extremely close to zero.

It was also necessary to amplify the signal in order to obtain correct readings. During this process the original signal is squared in order to maintain the signal curvature unchanged. This approach led to another problem regarding the signal analysis, when a negative value is squared it becomes positive creating errors in the plot. The solution passed by forcing the values to be always positive before squaring them. This is achieved by adding a safe value to the sensor readings.

$$
x=(\text { SensorValue }+ \text { SafeValue })^{2}
$$

As the values of the gravity sensor range from $-10 \mathrm{~m} / \mathrm{s}^{2}$ to $10 \mathrm{~m} / \mathrm{s}^{2}$, the value chosen to the SafeValue was 5. The value that is being used to process the movement is the $x$.

Finally it was necessary do apply a low-pass filter in order to smooth the data. The weighted smoothing filter used is described on the Chapter 4 (Section 4.4.3). In this case, the value received by the low-pass filter is the $x$ from the equation 5.1. 


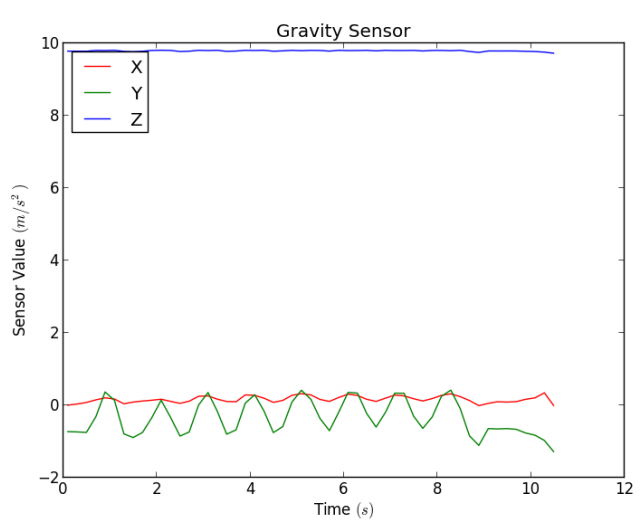

(a) Raw Signal

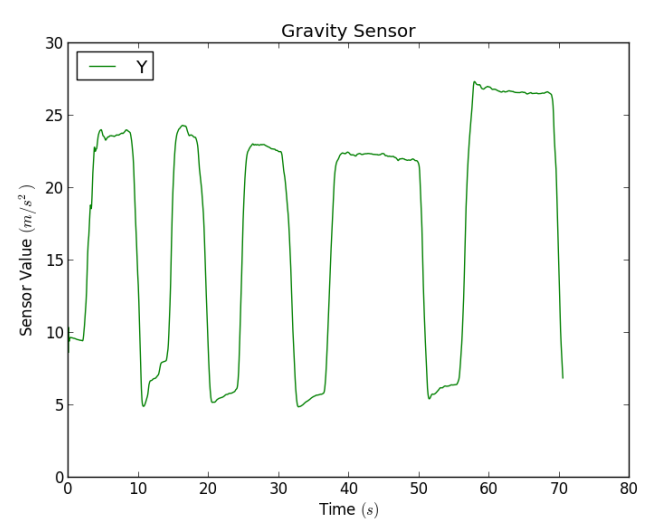

(b) Processed Signal

Figure 5.5: Plantar Flexion recorded with gravity sensor.

This signal processing produces a much linear plot, as it is visible on the Figure 5.5b. In this case, it is possible to clearly see the five local maximums of the Y-axis gravity corresponding to four plantar flexion movements. The main problem associated with this approach is that the values on the graphic cannot be easily associated to the normal value of gravitational acceleration, around $9,8 \mathrm{~m} / \mathrm{s}^{2}$.

\subsection{Sit to Stand}

Probably this is the most common activity performed during our daily tasks. The goal of this exercise is simply sitting and standing of a chair a pre-determined number of times (Figure 5.6a). In this exercise the movement performed can be is easily detected, due to the big smartphone variation that starts the movement parallel to the ground and during the exercise execution it becomes perpendicular to the ground. These variations are displayed in Figure 5.6b, where are the Z-axis and $\mathrm{Y}$-axis are subject to variations bigger than $5 \mathrm{~m} / \mathrm{s}^{2}$.

In the same way as the plantar flexion and ankle dorsiflexion (Section 5.3) the normal refresh rate of the sensors is too slow to detect the movements at the exact moment they occur. Therefore it was necessary to use the Gamest rate, this rate is not as fast as the Fastest use before but it is sufficient to detect the movements, and at the same time it save more battery.

This exercise can be decomposed in three distinct phases requiring evaluation. For each phase the duration time, the average duration and standard deviation of the full set of repetitions is evaluated. The first one is the complete cycle of standing and sitting from a chair, while the others are a subset of this one, namely the cycle of sit to stand and the stand to sit. 


\section{Exercise Processing}

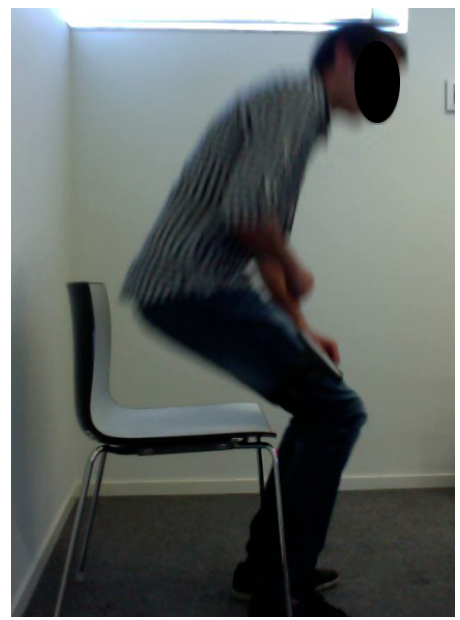

(a) Exercise Illustration

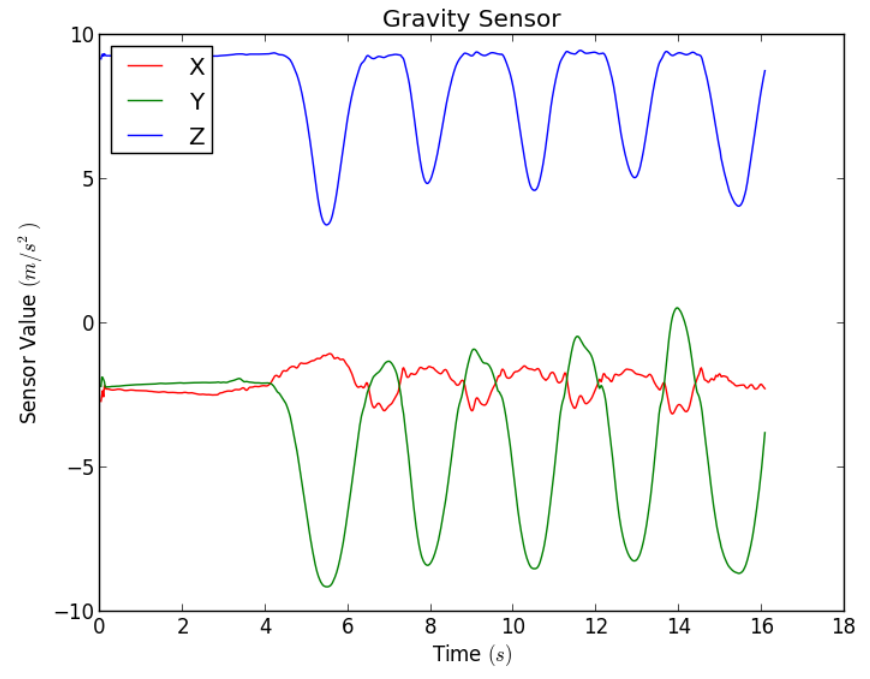

(b) Signal

Figure 5.6: Sit to Stand recorded with gravity sensor.

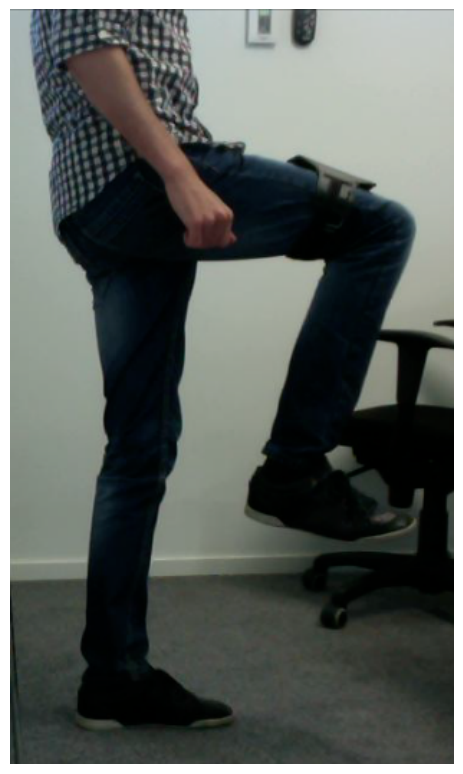

(a) Exercise Illustration

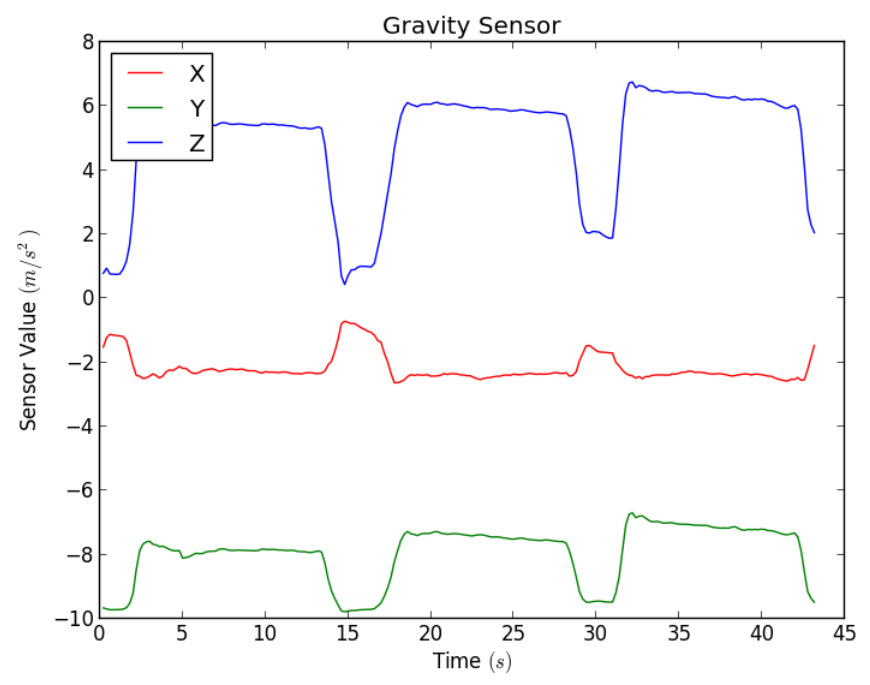

(b) Signal

Figure 5.7: Single Leg Stance recorded with gravity sensor. 


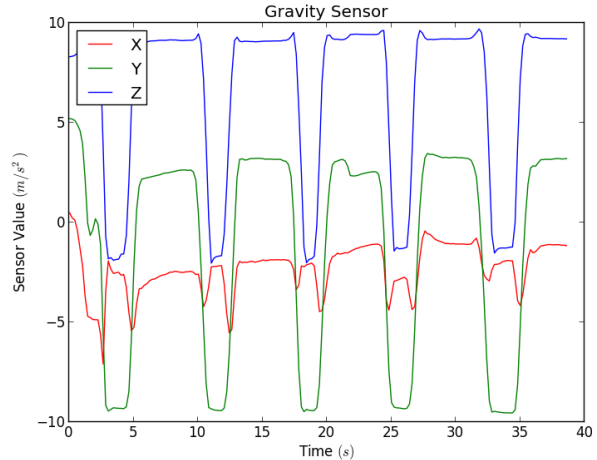

(a) Gravity Sensor

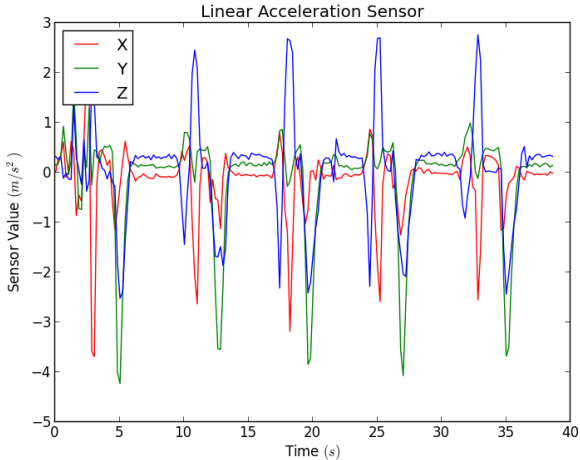

(b) Linear Acceleration Sensor

Figure 5.8: Reaching Forward recorded with gravity and linear acceleration sensors.

\subsection{Single Leg Stance}

The single leg stance exercise does not require the support of a chair. In this exercise the user is standing up and must stand in a single leg during a pre-defined period of time, as illustrated in Figure $5.7 \mathrm{a}$. The evaluation of this exercise is made using the value of the angle produced by the smartphone and the vertical.

In this case the initial position of the smartphone is perpendicular do the ground and it has a threshold value to define the angle value in which the leg is considered to have left the ground. As in the previous exercises it is possible to have a clear perception of the smartphone positioning alterations in Figure 5.7b.

\subsection{Reaching Forward}

As the single leg stance exercise (Section 5.5) the user is standing up without the support of a chair. The exercise starts with the arms parallel to the body (Figure 5.9a) and consists in raising both arms in front of the body until they are parallel with the ground as in Figure 5.9b.

In addition to the execution time and the number of repetitions it is also calculated the maximum reached angle by the arm. As in the previous exercises, the normal rate for the gravity sensor and linear acceleration is used.

The evaluation of this exercise is performed by the gravity sensor (Figure 5.8a), but this evaluation only starts after being detect an acceleration from the bottom to the top as shown in Figure $5.8 \mathrm{~b}$, in combination with the detection of the smartphone's position alteration.

\subsection{Evaluated Metrics}

Each exercise has a few associated metrics that need to be collected in order to provide correct feedback to the user. Those metrics can be found in Table 5.1; 


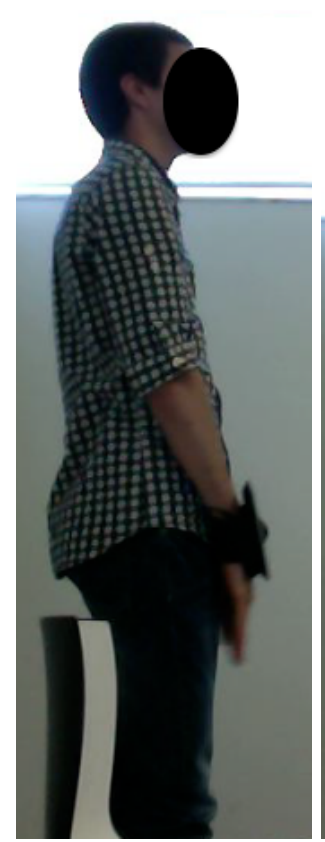

(a) Initial Position

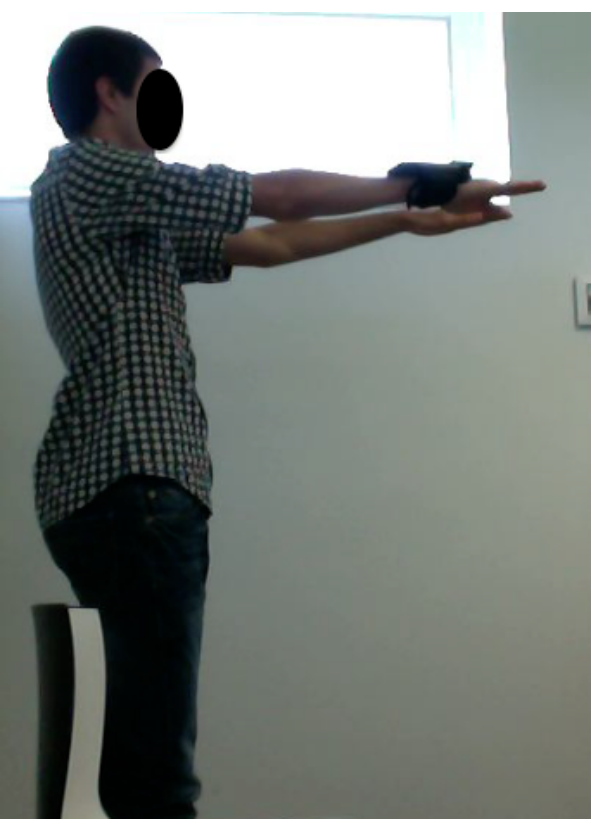

(b) Reaching Forward

Figure 5.9: Reaching forward exercise illustration.

Table 5.1: Metrics collected in each exercise.

\begin{tabular}{|c|c|}
\hline Exercise & Metrics Collected \\
\hline Extension of the Thoracic Spine & $\begin{array}{c}\text { Number of executions; } \\
\text { Number of forced positions in each execution; } \\
\text { Angle between the arm and vertical; } \\
\text { Time held in position; }\end{array}$ \\
\hline Upper Limb Elevation & $\begin{array}{c}\text { Number of executions; } \\
\text { Number of forced positions in each execution; } \\
\text { Time held in position; }\end{array}$ \\
\hline Plantar Flexion and Ankle Dorsiflexion & $\begin{array}{l}\text { Number of executions; } \\
\text { Time held in position; }\end{array}$ \\
\hline Sit to Stand & $\begin{array}{l}\text { Number of executions; } \\
\text { Mean and Std. Deviation of the sit to stand cycle; } \\
\text { Mean and Std. Deviation of the stand to sit cycle; } \\
\text { Mean and Std. Deviation of the complete cycle; }\end{array}$ \\
\hline Single Leg Stance & $\begin{array}{l}\text { Number of executions; } \\
\text { Time held in position; }\end{array}$ \\
\hline Reaching Forward & $\begin{array}{l}\text { Number of executions; } \\
\text { Angle between the arm and vertical; } \\
\text { Time held in position; }\end{array}$ \\
\hline
\end{tabular}




\section{Chapter 6}

\section{Validation and Evaluation}

On this section, the evaluation methodology and objectives are detailed. The aim of the used methodology is to provide some results concerning the developed algorithms, movement's detection and metric's evaluation. Analysing these results it is possible to evaluate the final solution, as well as identify the gaps that need to be improved in order to obtain a more accurate solution.

Additionally it is performed a simultaneously discussion of the results for each exercise.

\subsection{Evaluation Method}

\section{Participants}

Two different groups, both with 5 participants, participated on the evaluation study. The first group was a group of elderly people with mean age of $72 \pm 6$, while the other group was aged $23 \pm 1$ years old.

The inclusion of these two groups enabled the evaluation of the application performance on movement analysis regardless the individual's physical condition and health situation. As these groups have different motor abilities it was possible to have a more complete evaluation.

\section{Test Scenario}

In order to evaluate the designed application it was necessary to gather all the necessary material for the exercise realization. A simple armless chair, an armband capable of being used on the wrist and on the thigh and a smartphone, comprises all the required material.

According to the set of the exercises, the smartphone was placed inside an armband that was positioned on the wrist or thigh as necessary. Then each subject was asked to perform the exercises following a test protocol where the exercises they needed to perform were explained as well as the number of repetitions and the duration of each repetition. 


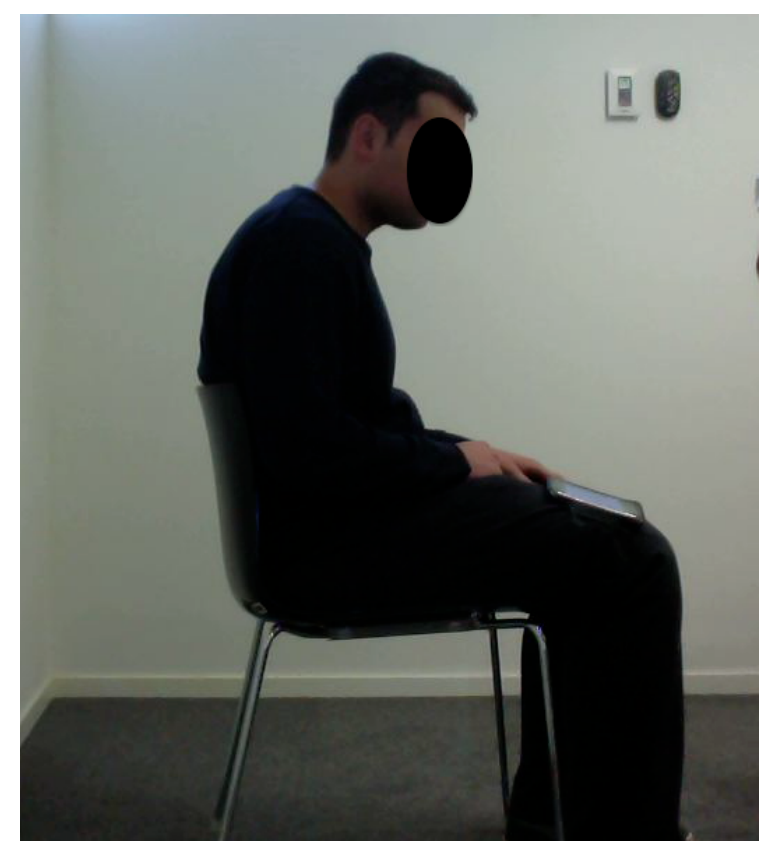

Figure 6.1: Tests Scenario.

During each exercise execution a simultaneous recording of the exercise with a digital video camera (recording 30 frames per second) and with the smartphone sensors was done. The camera was positioned parallel to the ground during exercises execution, and the full range of motion was recorded (Figure 6.1).

\section{Data Analysis}

The values obtained by the smartphone were compared with those recorded with the digital video camera. The solution found to compare both values was filming the subject while performing the exercises and afterwards measure the differences between those values and the values recorded by the smartphone.

Each exercise has its own metrics and therefore it is necessary to evaluate them individually. A frame by frame analysis was performed in order to determine the duration of each repetition, the number of repetitions and in some exercises the maximum angle reached during each repetition as well as the number of forced position in each repetition.

In order to measure the angle performed in each frame was necessary to use another application capable of doing it. In this case it was used the PixelSictk ${ }^{\circledR}$, a tool for measuring distances and angles for Mac Os ${ }^{\circledR} \mathrm{X}$, as illustrated on Figure 6.2.

In order to determine that there is no evidence that the values read in both situations are different is was used a statistical test, the paired t-test to compare the average metrics' values for smartphone and video readings. In this analysis it is also necessary to bear in mind that frame by frame analysis induce some errors on the evaluation process. 


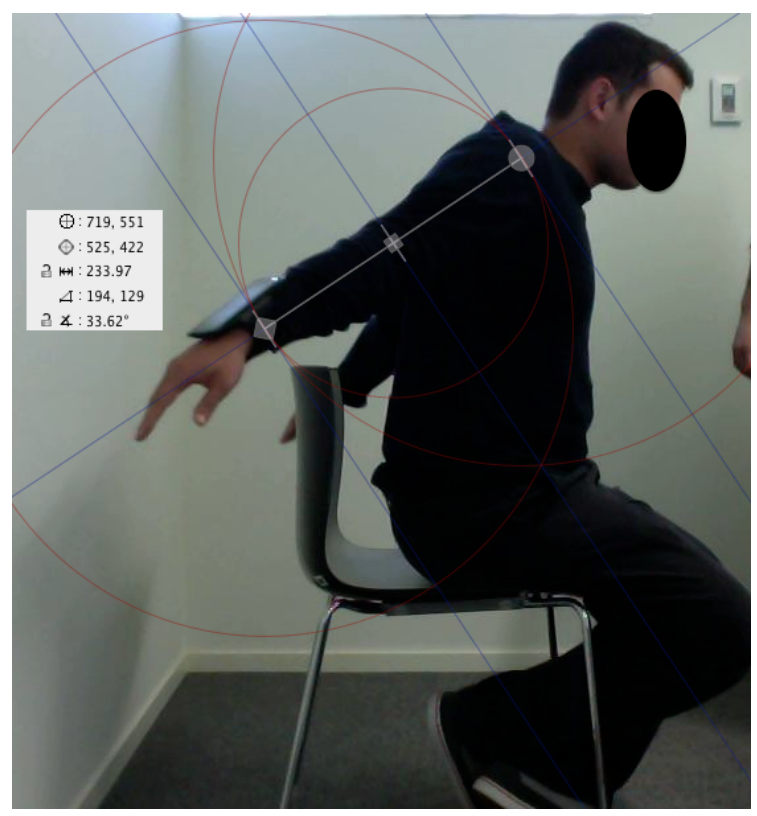

Figure 6.2: Illustration of the angle performed between the arm and vertical.

\subsection{Results}

Despite being part of a fall prevention programme, and having similar metrics to process, these exercises are performed individually and therefore they must be evaluated individually. With this individual evaluation it is possible to achieve more accurate results and conclusions.

\section{Plantar Flexion, Ankle Dorsiflexion and Single Leg Stance}

Regardless their differences these exercises have the same metrics, and therefore it is possible to join them in the same results analysis. The plantar flexion and ankle dorsiflexion were executed with a set of 5 executions for each subject, while the single leg stance was executed with a set of 3 executions.

The 10 subjects executed each exercise and the duration time recorded by the smartphone, in each repetition, was the same as recorded by the digital video camera; this occurs as the recorded execution time is the maximum time pre-defined for these exercises. The same appends with the number of repetitions for each exercise, in each the number of repetitions recorded by the smartphone are the same as in the video.

While the plantar flexion and single leg stance were able to detect and process correctly the exercises performed by the 10 subjects, the ankle dorsiflexion was only capable of detect the movements in 9 subjects. This occurs due to the influence of the chair size together with the user leg length, have in the sensors' values when the smartphone is located on the thigh. With a total of 50 valid repetitions it was unable to detect $10 \%$ of those executions, what is equivalent to the reads of one subject. 
Validation and Evaluation

Table 6.1: Upper Limb Elevation statistic.

\begin{tabular}{cccccc}
\hline Readings & Mean & Std. Deviation & T & Df & Sig. (2-Tailed) \\
\hline \hline $\begin{array}{c}\text { Smartphone } \\
\text { Video }\end{array}$ & 9,68 & 5,26 & $-1,20$ & 49 & 0,23 \\
\hline
\end{tabular}

\section{Upper Limb Elevation}

The upper limb elevation has a total of three metrics. The first two can be easily analysed and they are the number of executions and the execution time of each repetition. Every subject was asked to perform a full set of the exercise.

Each set of exercise had 5 executions of 10 seconds each, both of the metrics were totally collected and analysed by the smartphone and were equal to the video analyse results. As these metrics were equal to every subject, and had the same results, they do not require further analysis.

The other metric is the number of forced positions that were detected in each position, as these values are extremely variable it was necessary to perform the paired t-test analysis. As shown in Table 6.1 there was no significant difference in the values for the smartphone $(M=9,68, S D=5,26)$ and video $(M=9,88, S D=5,38) ; t(49)=-1,20, \rho=0,23$, within a $95 \%$ confidence interval. Since the value of the 2-tailed is 0,23 it is possible to conclude that there is no statistically significant difference between the two readings.

Additionally it is possible to see in Figure 6.3 the differences between each value read by the smartphone and gathered from the digital video camera. It is therefore possible to say that the upper limb elevation is being processed correctly by the smartphone.

\section{Extension of Thoracic Spine}

Like in the upper limb elevation exercise the subjects performed a full set of the exercise. This full set consists in 5 executions of 10 seconds each, where are collect metrics regarding the number of executions, execution time, the number of forced positions and additionally the angle performed between the arm and the vertical.

Following the same approach of the previous exercises there was not made further analysis regarding the executions and execution time, but it was performed a paired t-test for the other two metrics (the number of forced positions and angle).

In Table 6.2 is possible two analyse both metrics and see that there is no significant difference in the angle values for the smartphone $(M=57,23, S D=12,94)$ and video $(M=$ $56,86, S D=12,66) ; t(49)=0,71, \rho=0,47$, within a $95 \%$ confidence interval. The same appends with the number of forced positions values for the smartphone $(M=8,92, S D=$ $5,75)$ and video $(M=9,02, S D=5,96) ; t(49)=-0,49, \rho=0,62$, within a $95 \%$ confidence interval. 


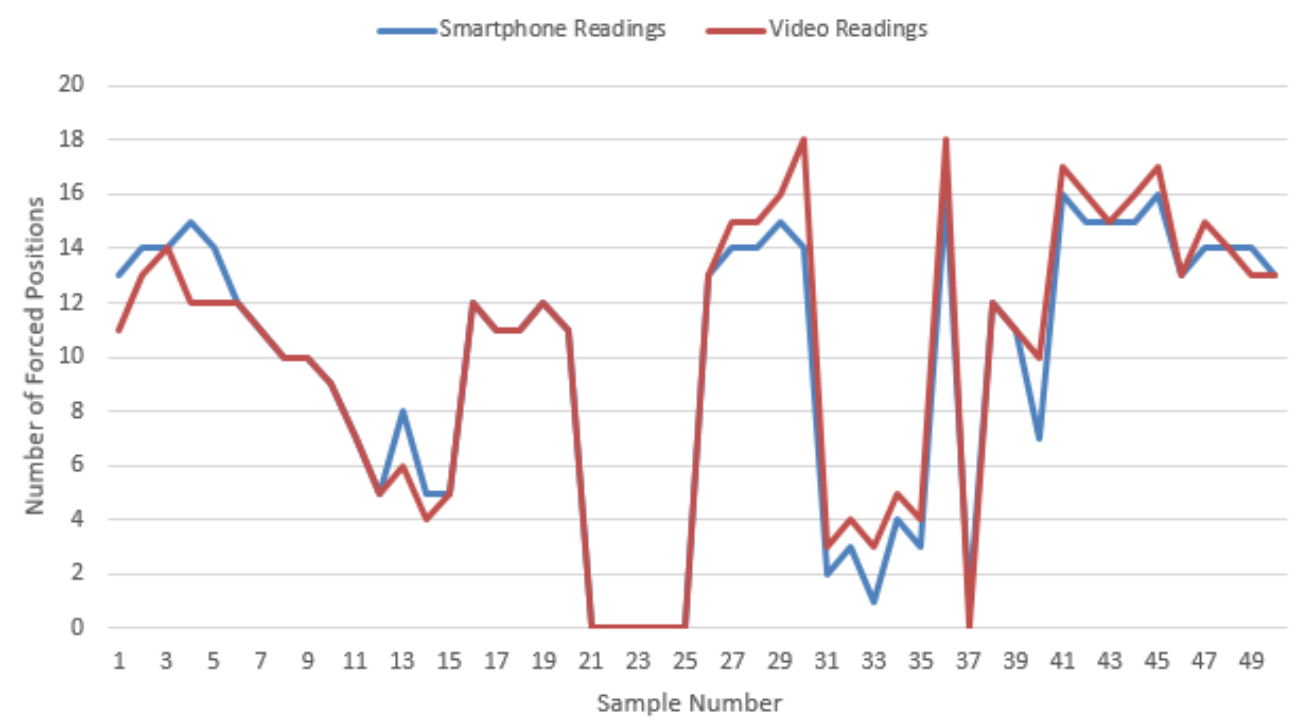

Figure 6.3: Comparison between the number of forced positions on the smarphone and on the video values in Upper Limb Elevation.

Since the value of the 2-tailed is 0,47 for the angle analysis and 0,62 for the repetitions analysis it is possible to conclude that there is no statistically significant difference between the two readings for both cases.

In Figure 6.4 it is possible to see the differences between each value read by the smartphone and gathered from the video for both angle values (Figure 6.4a) and number of forced positions (Figure 6.4b). Therefore it can be said that the extension of thoracic spine is being processed correctly by the smartphone.

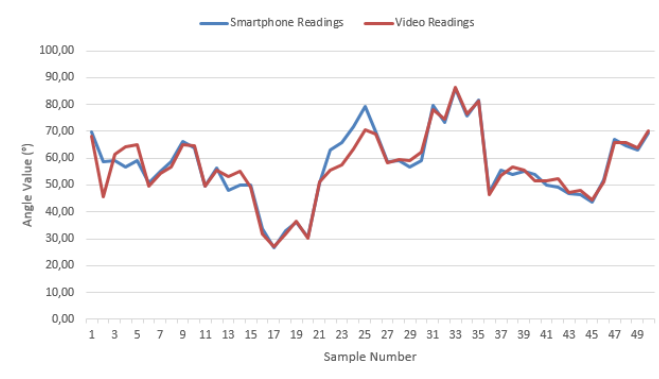

(a) Angle Readings

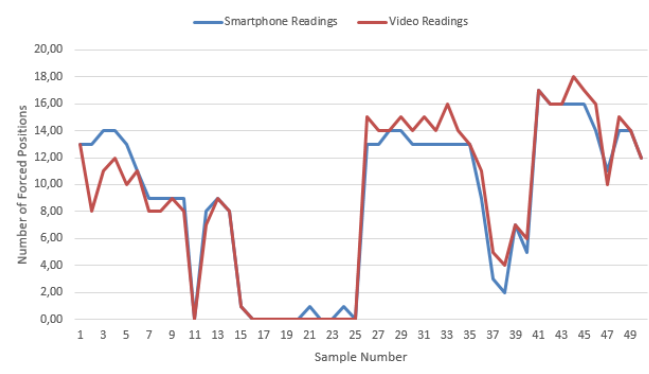

(b) Repetitions Readings

Figure 6.4: Comparison between the number of forced positions and angle values on the smarphone and on the video values in Extension of Thoracic Spine. 
Validation and Evaluation

Table 6.2: Extension of Thoracic Spine statistic.

\begin{tabular}{|c|c|c|c|c|c|c|}
\hline Value & Readings & Mean & Std. Deviation & $\mathbf{T}$ & Df & Sig. (2-Tailed) \\
\hline \multirow{2}{*}{ Angle } & Smartphone & 57,23 & 12,94 & \multirow{2}{*}{0,71} & \multirow{2}{*}{49} & \multirow{2}{*}{0,47} \\
\hline & Video & 56,86 & 12,66 & & & \\
\hline \multirow{2}{*}{ Forced positions } & Smartphone & 8,92 & 5,75 & \multirow{2}{*}{$-0,49$} & \multirow{2}{*}{49} & \multirow{2}{*}{0,62} \\
\hline & Video & 9,02 & 5,96 & & & \\
\hline
\end{tabular}

\section{Reaching Forward}

On the reaching forward exercise each subject raised their arms parallel to the ground and hold the position for 3 seconds, in this case a full set of the exercise consists in 5 executions. In this exercise, both readings of executions and duration time of the execution where consistent and it was not done any extra analysis.

The other metric of this exercise, the angle performed by the arm with the vertical, required further statistical analysis that was performed with a paired t-test. As shown in Table 6.3 there was no significant difference in the angle values for the smartphone $(M=$ $101,60, S D=6,17)$ and video $(M=101,93, S D=6,88) ; t(49)=-0,71, \rho=0,48$, within a $95 \%$ confidence interval.

As shown by the Figure 6.5 and the value of 0,48 of the 2-tailed is possible to conclude that there is no statistically significant difference between the two readings. As the previous exercises it is possible to say that reaching forward processing is working as expected.

\section{Sit to Stand}

The exercise analysed here is the sit to stand, which for purposes of evaluation must be seen as a set of three exercises, the full sit to stand cycle, the sit to stand duration and the stand to sit duration.

Before proceeding to a more individual analysis it is important to say that as appends in previous exercises, the subject performed a full set of the exercise, but in this case there was no predefined time to perform the 5 executions. One of the evaluated metrics is the number of executions, that as appends in previous exercise it is a predetermined number that was perfectly measured by the smartphone. Being therefore necessary to evaluate the other metric collected, the duration of each execution.

Starting by the full cycle of sit to stand and analysing the results shown in Table 6.4 and Figure 6.6 the first value that requires attention is the $\mathrm{df}$ value. Comparing with the previous exercises where the value of df was 49 representing a total of 50 executions, in this case we only have a df value of 41 , representing a total of 42 evaluated executions.

This gap between the values occurred due to faulty readings by the smartphone, meaning that the application were unable to detect the movement. This represents $16 \%$ of faulty readings. 
Table 6.3: Reaching Forward statistic.

\begin{tabular}{cccccc}
\hline Readings & Mean & Std. Deviation & T & Df & Sig. (2-Tailed) \\
\hline \hline $\begin{array}{c}\text { Smartphone } \\
\text { Video }\end{array}$ & 101,60 & 6,17 & $-0,71$ & 49 & 0,48 \\
\hline
\end{tabular}

Table 6.4: Sit to Stand statistic.

\begin{tabular}{cccccc}
\hline Readings & Mean & Std. Deviation & T & Df & Sig. (2-Tailed) \\
\hline \hline $\begin{array}{c}\text { Smartphone } \\
\text { Video }\end{array}$ & 2,11 & 0,36 & \multirow{2}{*}{1,50} & \multirow{2}{*}{41} & 0,14 \\
\hline
\end{tabular}

Analysing the valid readings with a paired t-test there is no significant difference in the duration values for the smartphone $(M=2,11, S D=0,36)$ and video $(M=2,08, S D=0,33)$; $t(49)=1,50, \rho=0,14$. Therefore it is possible to conclude that there is no statistically significant difference between the two readings, and that $84 \%$ of the times the full cycle of sit to stand has been correctly processed.

Analysing the Figure 6.7 it is clear the difference between the smartphone readings and the video readings, independently of being in the sit to stand duration (Figure 6.7a) or in stand to sit duration (Figure 6.7b).

In case of the sit to stand duration, this gap exists due to the different number of samples that are collected each second in the smartphone and in the video. While the video only collects 30 samples per second, the gravity sensor (which was used to evaluate this movement) has a frequency of $50 \mathrm{~Hz}$, corresponding to 50 samples per second. Therefore it is impossible to perform a precise evaluation required for this exercise, as the execution time is quite small.

On the other hand the existing error on the stand to sit is due to a faulty design application. In this case the stand to sit wasn't evaluated as a single exercise but as being part of the full sit to stand cycle. The approach chosen to evaluate this method was to subtract the duration of the sit to stand cycle on the full cycle duration, but once the user do not start the process of sitting right after the stand, these readings becomes totally wrong, as it is possible to confirm in Figure 6.7b 
Validation and Evaluation

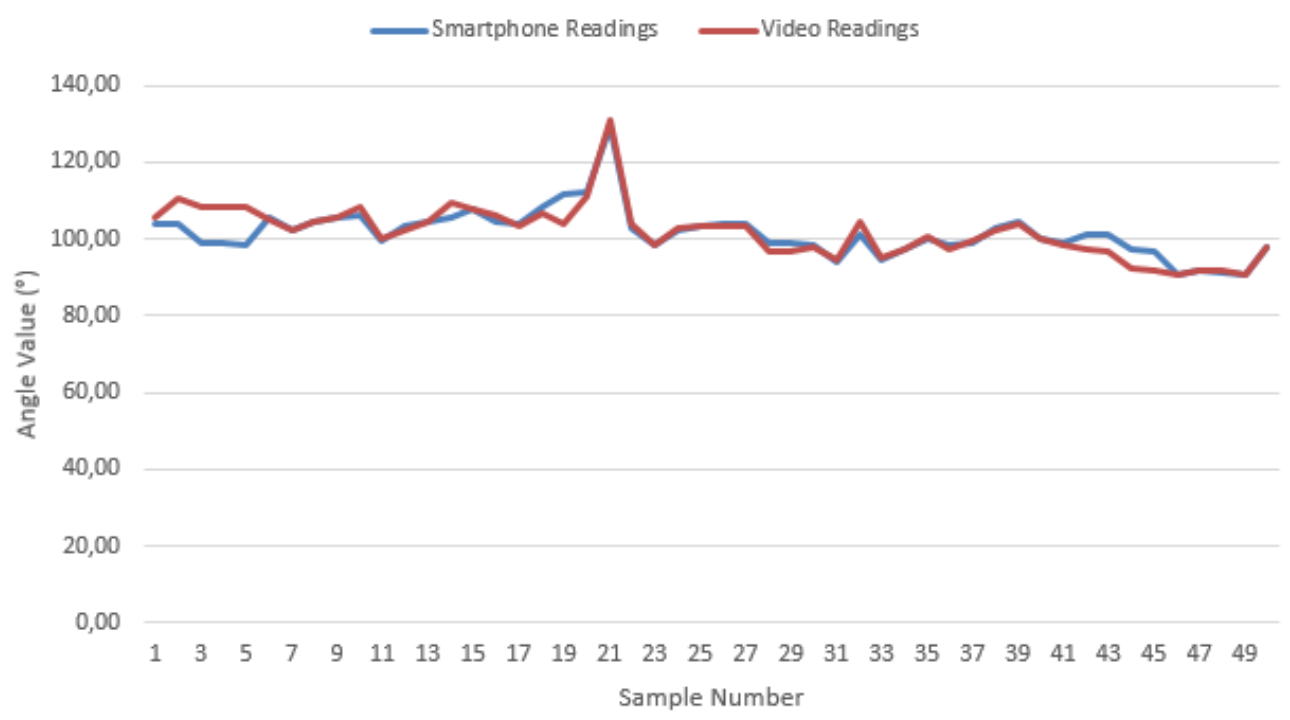

Figure 6.5: Comparison between the angle values on the smarphone and on the video values in Reaching Forward.

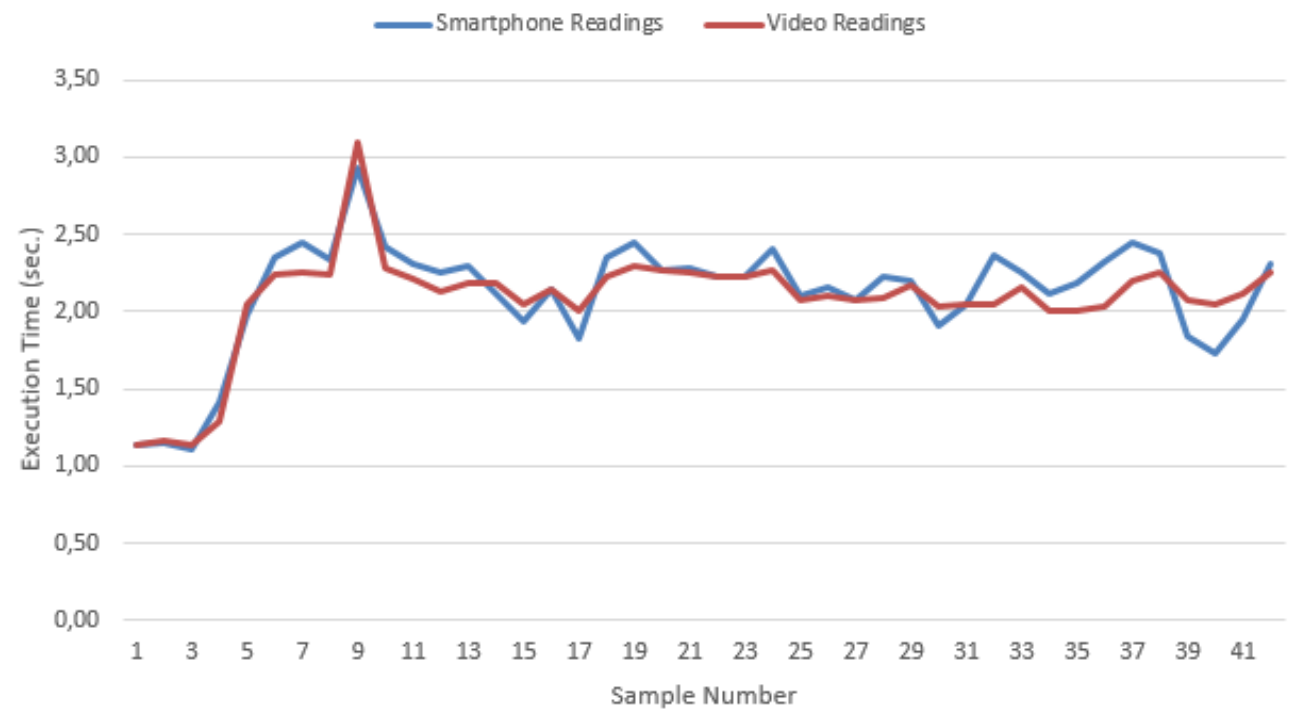

Figure 6.6: Comparison between the execution time on the smarphone and on the video values in the complete cycle of Sit to Stand. 
Validation and Evaluation

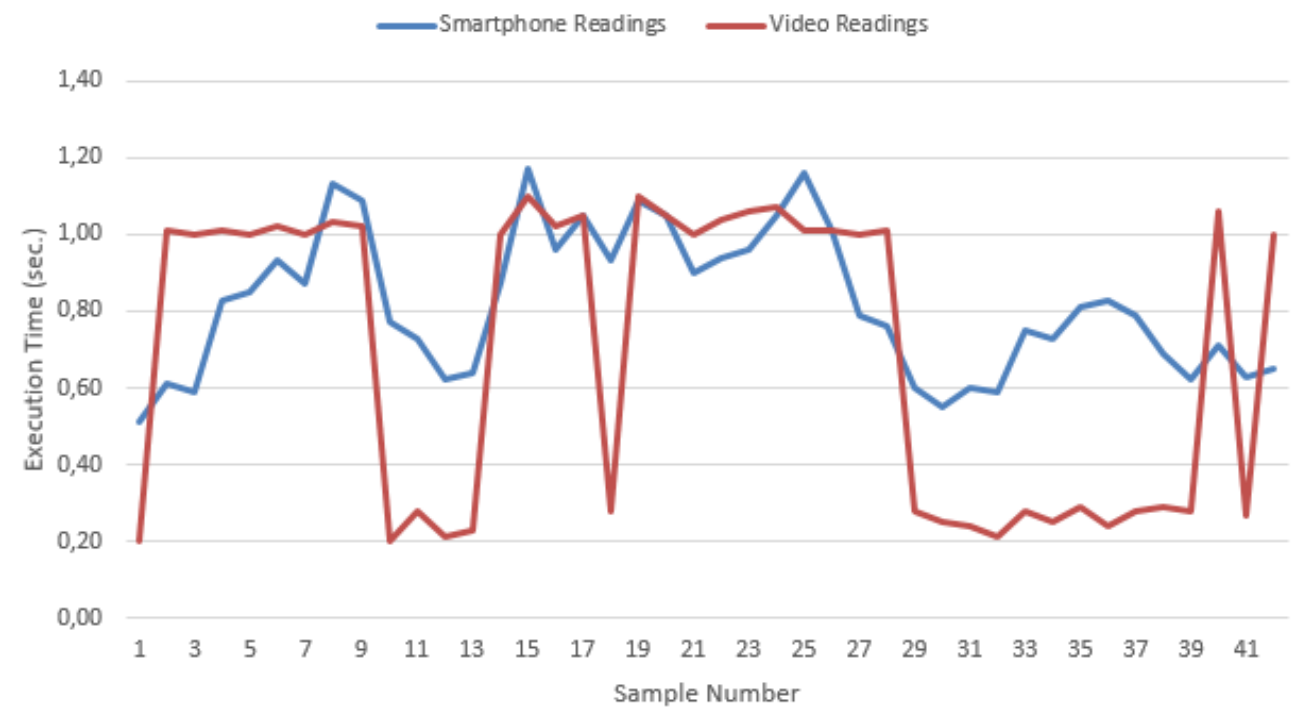

(a) Sit to Stand

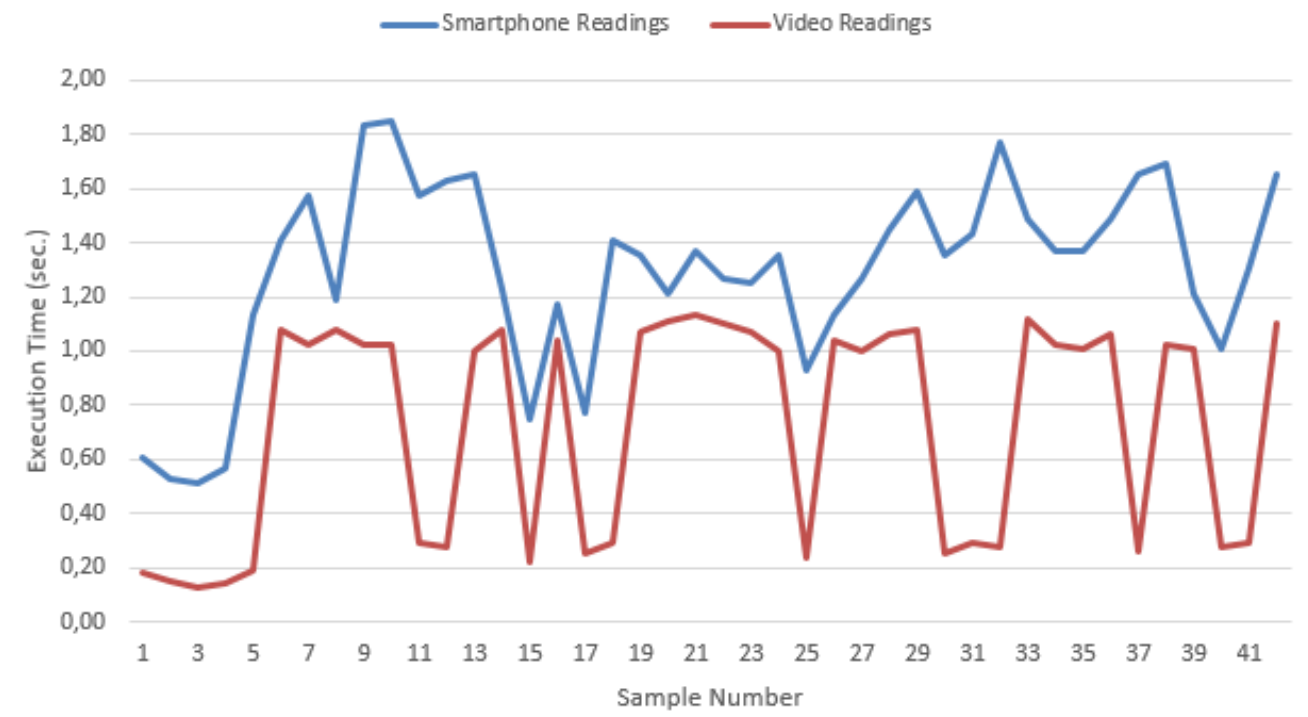

(b) Stand to Sit

Figure 6.7: Comparison between t execution time on the smarphone and on the video values in Sit to Stand and Stand to Sit. 
Validation and Evaluation 


\section{Chapter 7}

\section{Conclusions and Future Work}

With the increasing of life expectancy new problems arise for the society. One of these problems are the falls, which creates physical, psychological and social problems to the elderly as well as increases the health care costs to society. It is therefore important to improve the actual state of fall prevention.

With the increasing number of fall prevention programmes and the increasing costs associated with them, it was important to find a solution that leads these programmes to the elderly in a easy and affordable way. Therefore, this project presents a new approach to fall prevention exercises, and pretends to give to every elderly the opportunity of enrolling in a fall prevention programme in the comfort of his/her home, and more importantly without the need of external help.

Taking advantage of the available technologies in a smartphone, namely the inertial sensors and the power processing it was possible to develop a solution capable of evaluate fall prevention exercises regardless the user location with an increased motivation and comfort.

Using a single smartphone it was possible to develop an inexpensive solution capable of assisting elderlies during this phase of their life. Moreover, nowadays almost everyone has a simple smartphone that can be used for fall prevention purposes, and therefore there aren't any additional costs associated with it.

With this challenging project it was possible to create a solution capable of evaluate the exercises performance and, at the same time, capable of monitoring several parameters (metrics) that can be used to monitor the patient evolution. Another important contribution was the development of a method capable of collecting, processing and measure a set of fall prevention exercises, all these in a simple Android smartphone.

With the development of a prototype it was possible to demonstrate that this solution accomplish the purposed objectives of analyse and evaluation of user specific movements. Another advantage of the implemented prototype is that it is not dependent of the Android platform, as it is implemented in Java and do not take advantage of specific Android features. Therefore it can be easily adapted to others operating systems. 
The main drawback of the all project is the initial approach of using a single smartphone, as it is only possible to evaluate the movements performed by a single upper limb and a single lower limb. To summarize, it was possible to achieve a final solution, that is portable, small, easy to use and always available regardless the user location.

\subsection{Lessons Learned}

The process of creating a solution capable of correctly process the fall prevention exercises was quite challenging, and therefore it is important to make some considerations regarding this process.

Firstly it is important to have in mind that with the threshold approach it is impossible to define the most appropriated value for each situation as the exercise execution differs from user to user. Even with the same user the exercise may vary from time to time. Therefore when designing these kind of algorithms it is necessary to increase the thresholds tolerance, creating a safe value that do not compromises the narrow relation between a correct movement detection or a false movement detection.

Additionally when developing tools for detection and analysis of users movement it is necessary to take into account that may exist several physical differences between each individual, and in this specific project, it is also necessary to take into account the different of heights between the chairs used by users. These situations have influence in the smartphone initial position, and consequently differences in the thresholds, requiring adjusting them for each situation.

These adjustments require some time in a static position in order to get calibration data that enable to adjust the upcoming sensor readings according to the initial smartphone positioning. However, users may not be willing to wait for the calibration process, therefore it is done a quick calibration and during the exercises executions more adjustments are made to the sensors values. The main drawback of doing this evaluation on the background is the small number of samples that can be collected and processed during the exercise execution.

Finally, and regarding the chosen positions for the smartphone it is possible to say that the set of exercises performed with the smartphone on the leg are less propitious to involuntary errors. On the other hand, the set of exercises with focus on the arms are much more unstable, as they are more likely to induce random movements and therefore introduce misleading information that can be processed inaccurately.

\subsection{Future Work}

Considering the results obtained with this project, and having in mind the main goal of fall prevention programmes and target audience, it was possible to identify a few potential improvements for the application. Some of those future tasks are listed bellow.

- The first potential improve suggested is the creation of an interface were the user can follow his/her exercise evolution in an simple and interactive way. 
- As these exercises are designed to be performed alone at patient's home or institution, they may have a motivational problem. This can be overcome with the adaptation of these exercises into a serious game. Additionally this serious game, or a set of small exercises, can be complemented with a social approach where the users are able to play against each other in a community.

The game design need to have into account the small dimensions of the smartphone screen as well as that during the exercise execution it is hard to see the smartphone screen. To overcome this problem the interaction may be done through audio, playing specific sounds at predetermined positions of the exercise execution.

Another solution may pass through the use of a set-top box like the Google TV connected to the smartphone. In this scenario the video game interaction is done through the television, increasing the interaction levels.

- The actual user experience has a few handicaps regarding the smartphone location and the necessity of changing it between positions. One solution may be the addition of a set of external inertial sensors capable of directly interact with the smartphone. These external sensors must be able to transmit the data through Bluetooth to the smartphone, creating a new solution that can be easily integrated with the actual solution. The new sensors could be placed on the user's leg and arm reducing the need of changing the smartphone position according to the exercise performed.

- A key factor for the success of a fall prevention programme is the interaction and supervision of the healthcare providers, therefore it is important for them to keep up with the patient evolution. This can be accomplished by sending the feedback provided to the user to the healthcare provider, for example, through the smartphone email.

- This solution might even evolve into an online platform where the patients can be constantly monetized by every involved parts, such as the healthcare providers, the patient and the patient's family. With an online platform the healthcare providers can easily communicate with the patient and also make changes to the number of executions and the execution duration of each exercise, therefore creating different exercise levels, more challenging, according to the patient capabilities and evolution.

- Evaluate the battery consumption and analyse if some improvements are required to save the battery lifetime, as sensors usage consumes a high amount of energy. 
Conclusions and Future Work 


\section{References}

[AdMC11] Trew M Argel de Melo C, Kuisma R. A preventive, specific and moderate exercise programme on fall risk factors in older portuguese people. the journal of nutrition, health and aging, 2011.

[BA03] Lord S Williams M Baumand A Barnett A, Smith B. Community-based group exercise improves balance and reduces falls in at-risk older people: A randomized controlled trial. Age and Ageing, 2003.

[BCCP12] W. Boontarig, W. Chutimaskul, V. Chongsuphajaisiddhi, and B. Papasratorn. Factors influencing the Thai elderly intention to use smartphone for e-Health services. 2012 IEEE Symposium on Humanities, Science and Engineering Research, pages 479-483, June 2012.

[Bha13] Shashank Bhardwaj. Will the pc die? Available at http://www.geekinsider. com/2013/01/28/will-the-pc-die/ in 09 June 2013, 2013.

[Bur10] Ed Burnette. Hello, Android: Introducing Google's Mobile Development Platform. Pragmatic Programmers, LLC, 2010.

[eMa13] eMarketer. Three out of four uk mobile users to own smartphones by 2016. Available at http://www.emarketer.com/Article/ Three-of-Four-UK-Mobile-Users-Own-Smartphones-by-2016/ 1009614 in 09 June 2013, 2013.

[FAM06] FAME. Fitness and mobility exercise program: A community-based group exercise program for people living with stroke, 2006.

[fDCP12] Centers for Disease Control and Prevention. Falls among older adults: An overview. Available at http://www.cdc.gov/HomeandRecreationalSafety/Falls/ adultfalls.html, accessed in 09 January 2013, September 2012.

[GG12] Go-Gulf. Smartphone users around the world - statistics and facts [infographic]. Available at http://www.go-gulf.com/blog/smartphone/ in 19 May 2013, 2012.

[GOH ${ }^{+}$96] W C Graafmans, M E Ooms, H M Hofstee, P D Bezemer, L M Bouter, and P Lips. Falls in the elderly: a prospective study of risk factors and risk profiles. American journal of epidemiology, 143(11):1129-36, July 1996.

[Goo13] Google. Android. http://www.android.com/about/, accessed in 30 January 2013, 2013. 


\section{REFERENCES}

[HLN09] E Heiden, Y Lajoie, and A Nativ. Games-based biofeedback training applications in rehabilitation and fall prevention, 2009.

$\left[\mathrm{HOT}^{+}\right.$09] Jeffrey Halter, Joseph Ouslander, Mary Tinetti, Stephanie Studenski, Kevin High, and Sanjay Asthana. Hazzard's Geriatric Medicine and Gerontology, Sixth Edition (Principles of Geriatric Medicine \& Gerontology). McGraw-Hill Professional, 2009.

[Inc] Google Inc. Android api guides. Available at http://developer.android. com/guide/components/index.html in 09 May 2013.

[INdE12] I.P. Instituto Nacional de Estatísticas. Indicadores sociais 2011. Available at http://www.ine.pt/xportal/xmain?xpid=INE\&xpgid=ine_ publicacoes \&PUBLICACOESpub_boui=149279938\&PUBLICACOESModo=2, accessed in 09 January 2013, 2012.

[JGG04] Stephen Brewster Joy Goodman and Philip Gray. Older people, mobile devices and navigation. Proceedings of the Workshop on HCI and the Older Population, 2004.

$\left[\mathrm{JKK}^{+} 12\right]$ Michael John, Stefan Klose, Gerd Kock, Michael Jendreck, Richard Feichtinger, Ben Hennig, Norbert Reithinger, Jörn Kiselev, Mehmet Gövercin, Elisabeth SteinhagenThiessen, Stefan Kausch, Marco Polak, and Boris Irmscher. SmartSenior's Interactive Trainer - Development of an Interactive System for a Home-Based Fall-Prevention Training for Elderly People. Springer Berlin Heidelberg, 2012.

[KSP ${ }^{+}$05] Pekka Kannus, Harri Sievänen, Mika Palvanen, Teppo Järvinen, and Jari Parkkari. Prevention of falls and consequent injuries in elderly people. The Lancet, 366(9500):1885 - 1893, 2005.

[McK12] Joe McKendrick. Milestone: more smartphones than pcs sold in 2011. Available at http://www.smartplanet.com/blog/business-brains/ milestone-more-smartphones-than-pcs-sold-in-2011/21828 in 09 June 2013, 2012.

[MS10] G. Milette and A. Stroud. Professional Android Sensor Programming. Wiley, 2010.

[MTS $\left.{ }^{+} 12\right]$ S Mellone, C Tacconi, L Schwickert, J Klenk, C Becker, and L Chiari. Smartphonebased solutions for fall detection and prevention: the FARSEEING approach. Zeitschrift für Gerontologie und Geriatrie, 45(8):722-7, December 2012.

[Org07] World Health Organization. Who global report on falls prevention in older age. Available at http://www.who.int/ageing/publications/Falls_ prevention7March.pdf, accessed in 23 November 2012, 2007.

$\left[\mathrm{OYY}^{+} 10\right]$ H Onodera, T Yamaguchi, H Yamanouchi, K Nagamori, M Yano, Y Hirata, and $\mathrm{K}$ Hokkirigawa. Analysis of the slip-related falls and fall prevention with an intelligent shoe system, 2010.

[Por13] Fraunhofer Aicos Portugal. Dance don't falll. http://dancedontfall. projects.fraunhofer.pt/, accessed in 15 January 2013, 2013.

[SAOM12] N Shiozawa, S Arai, S Okada, and M Makikawa. Gait analysis of sit-to-walk motion by using portable acceleration monitor device for fall prevention, 2012.

[SH11] Dave MacLean Sayed Hashimi, Satya Komatineni. Pro Android 3. Apress, 2011. 


\section{REFERENCES}

[SLC08] Catherine Sherrington, S Lord, and J Close. Best practice recommendations for physical activity to prevent falls in older adults. North Sydney: NSW, (November 2008), 2008.

[SS10] Suziah Sulaiman and Intan Suriany Sohaimi. An investigation to obtain a simple mobile phone interface for older adults. International Conference on Intelligent and Advanced Systems (ICIAS), 2010.

[SSS $\left.{ }^{+} 11\right]$ S T Smith, C Sherrington, S Studenski, D Schoene, and S R Lord. A novel Dance Dance Revolution (DDR) system for in-home training of stepping ability: basic parameters of system use by older adults. British journal of sports medicine, 45(5):4415, May 2011.

[tpfioa03] Otago Exercise Programme to prevent falls in older adults. A home-based, individually tailored strength and balance retraining programme. prevention, care, recovery, 2003 .

[TS04] C Todd and D Skelton. What are the Main Risk Factors for Falls Amongst Older People and what are the Most Effective Interventions to Prevent These Falls? (March), 2004.

[WH91] JE Walker and J Howland. Falls and fear of falling among elderly persons living in the community: occupational therapy interventions. ... Journal of Occupational Therapy, 1991.

[Whi90] G. Robert Whitcomb. Computer games for the elderly. SIGCAS Comput. Soc., 1990. 
REFERENCES 


\section{Appendix A}

\section{Accepted Paper}

The following paper was submitted for the $15^{\text {th }}$ International Conference on E-Health Networking, Application and Services (IEEE-Healthcom'13) on $20^{\text {th }}$ May and accepted in $10^{\text {th }}$ July. 


\section{Smartphone Based Fall Prevention Exercises}

\author{
Bruno Neves Ferreira \\ Fraunhofer Portugal \\ Research Center for \\ Assistive Information and \\ Communication Solutions \\ FhP-AICOS \\ Porto, Portugal \\ bruno.ferreira@fraunhofer.com
}

\author{
Vânia Guimarães \\ Fraunhofer Portugal \\ Research Center for \\ Assistive Information and \\ Communication Solutions \\ FhP-AICOS \\ Porto, Portugal \\ vania.guimaraes@fraunhofer.com
}

\author{
Hugo Sereno Ferreira \\ Department of Informatics \\ Engineering \\ Faculty of Engineering, University \\ of Porto \\ INESC TEC (formerly INESC Porto) \\ Porto, Portugal \\ hugosf@fe.up.pt
}

\begin{abstract}
Falling is a very serious problem for our society, as it affects one out of three older adults. Currently, this is a wellknown problem and therefore multiple ICT-based solutions for falls management exist. In addition, a small part of them are said to help preventing falls, but most of the reviewed solutions doesn't seem to have their focus in reducing specific fall risk factors like loss of muscle mass or a poor balance. The proposed ICT-based fall prevention solution is based on an existing fall prevention exercise programme specifically designed for the Portuguese population. It takes advantage of the smartphone processing capabilities as well as its built-in inertial sensors to evaluate the movements performed during the execution of specific exercises. Using only a simple smartphone it is possible to provide a friendly and inexpensive solution capable of increasing seniors' adherence to fall prevention exercises as well as raise their motivation to properly execute the exercises in their home environment.
\end{abstract}

Keywords-Fall prevention; Smartphone; Android; Exercises; Falls; Older People; Inertial Sensors;

\section{INTRODUCTION}

Ageing is one of the biggest problems faced by our society. With the increase in life expectancy, it is projected that in 2015 $18,7 \%$ of European population will have more than 65 years old, against $15,6 \%$ of young people. Furthermore, this gap tends to increase through the upcoming years with the index of ageing growing up from 120 in 2015 to near 200 in 2050 [1].

Associated to an aging population, new social and economic problems arise, which constitutes a challenge to our society. Particularly, falls represent a serious and common problem affecting older persons, as this age group is particularly prone to falls and injuries. It is known that around the world one out of three seniors experience falls each year [2] and this number rises to nearly $50 \%$ when we are talking about institutionalized people [3]. The economic impact of falls is associated to health care costs that are particularly relevant when a fall leads into a serious injury, for example, a fracture, and the person tends to stay at the hospital for an extended period of time [3,4]. Additionally, a fall may create a fear of falling again, which will cause loss of independence and a reduced quality of life of the patient [4]. As elderly people are broadly affected by the occurrence of falls, it becomes extremely important to find ways to reduce the number of falls and consequently to improve their quality of life.

In order to reduce the number of falls, it is important to identify the most common fall risk factors and apply specific fall prevention strategies to reduce those risks. Reduced muscle strength, slowed pace of movements, poor balance and an obvious decrease of physical activity are some examples of fall risk factors [4]. An effective strategy to prevent falls is the practice of physical exercise, preferably targeting specific risks.

Physical exercises are known to improve older person's muscle mass, increase muscle strength, and more importantly, improve balance. Currently, several exercise programs exist and are suitable to be performed by the older person alone or in group, without compromising their safety [5,6,7]. Unfortunately, fall prevention exercises are rarely applied. This occurs due to the high costs of transportation to clinical environments where group exercises are performed in a daily or weekly basis [2,3]. Furthermore, when the senior is alone at home, he/she does not have the motivation required to perform these tiresome exercises. Having these problems in mind it is necessary to find solutions to increase the adherence to the fall prevention exercises, and also increase the awareness about the benefits these exercises represent to the older person, therefore increasing their motivation and the "treatment" compliance.

Most of these constraints can be overcome with today's technologies. Modern video game consoles, for example, are able to identify users' movements; therefore they can be used as a strategy to help users perform exercises at home. However, it will restrict the exercises execution to the place where the console is. Moreover a console can be quite expensive to be used as a facilitator of fall prevention exercises. Another technology available is the computer, or, preferably, due to its portability, the laptop $[11,12]$. The main disadvantage is that they require the connection of external devices to detect user movements and an additional configuration step, which might reduce the usability of the whole system.

When we think about new and emerging technologies we are thinking on tablets and smartphones, devices that are extremely powerful with high levels of mobility and usability. Both devices have built-in sensors that can be used to evaluate movements performed by the user. In particular, the smartphone, due to its reduced dimensions, can be attached to 
certain part of the body, being able to evaluate specific movements of the user.

The aim of this project is therefore to develop a smartphone-based solution capable of guiding an elderly person throughout a set of exercises in a safe and easy way, as well as evaluate and provide feedback about the user performance. This set of exercises is presented to the user as a serious game, increasing the motivation to perform them frequently at seniors' home.

\section{FALL PREVENTION EXERCISES}

Fall prevention exercises are not new in our society, and several programmes already exist, for example, the "Ortago Exercise Programme" used in New Zealand [5], and the FaME - Fall Management Exercise Intervention - applied in London [6].

A specific and moderate exercise programme was designed by Argel de Melo, C. et al. (2011) taking into account specific fall risk factors in older Portuguese people [7]. The programme was designed to be performed using only a chair as support. The use of a chair pretends to reduce the risk associated with the execution of the exercises without medical supervision. This was chosen program to be the basis of the smartphonebased fall prevention solution.

Due to some restrictions related to the size of the smartphone and the required positioning of the device (i.e. to enable the sensors to read meaningful data about the movement performed), not all of the exercises included in the programme were appropriate to be adapted to the smartphone. Therefore, those related to neck retractions and rotations were not considered for evaluation using the smartphone. Exercises focused on the thoracic spine, upper members, ankle and lower limbs were all selected to be included in the fall prevention tool. The extension of the thoracic spine is one of those exercises. It is performed with the elderly sitting on a chair and with arms abducted and external rotated, holding this position for a while, which will improve flexibility and muscle endurance.

Also, to improve the range of motion of the shoulder, an upper limb exercise is included. This exercise consists in a simple arm elevation until the maximum range is achieved, also holding this position for a certain amount of time. These two exercises together with the reaching forward exercise (that intends to amend balance) can be evaluated at the level of the arm; therefore, the smartphone can be maintained in the same position during the execution of this set of exercises.

Another set of exercises can be evaluated always in the same position, but in this case on the leg. Active ankle dorsiflexion and plantar flexion, performed in a seated position, will develop better gait mobility and therefore improve daily actions like stair climbing. The exercise of sitting down and standing up from a chair will be able to improve lower limb strength. Routine activities like dressing can also be improved with the single leg stance exercise, which will enhance equilibrium and therefore, avoid falls.
Finally, the last two recommended exercises are the voluntary stepping (in forward, lateral and backward direction), which reduce the sensation of balance loss, and walking every day, which improves gait speed and helps the user to keep active. To be effective, these exercises need to be performed regularly at home, which sometimes creates motivational problems on the senior and an interesting problem to be solved in order to keep prevention exercises effective.

\section{THE SMARTPHONE-BASED SOLUTION}

So far, several concerns were presented and need to be taken into account so that platform requirements are fulfilled. The platform must incorporate several sensors capable of detecting movement, acceleration, and relative position. In addition it must be programmable and allow the communication with the sensors. Nevertheless it must be affordable to the masses and have an easy and interactive interface specially adapted to elderly people.

Such requirements suggest the use of the Android platform which provides a wide set of tools that enable a full exploration of the smartphone capabilities. Android is an open source and free development platform based on Linux. The Linux kernel is the base of the whole platform and it is responsible for memory and process management, as well as networking and others system services on Android [8].

It also has a lot of built-in services out of the box like the GPS, gyroscope, accelerometer and magnetic sensor. In addition to it Android offers portability for current and future hardware. This portability is only possible because all of the programs that run in Android are written in Java and are executed by a virtual machine called Dalvik [8]. This virtual machine is optimized to compile the Java class files taking into account the device limitations such as memory, processor speed and power [9]. This design makes possible to write java code to be run on the device and therefore it is easy to develop to Android-based programs.

Android devices define two coordinate systems: one to represent the global coordinate system (i.e. the Earth) and one to represent the device coordinate system.

Inertial sensors are designed to measure motion. Accelerometer, gyroscope and magnetometer are some examples of sensors usually available in Android devices [10].

- The accelerometer, can sense tri-axial accelerations. The accelerometer on Android is a set of tiny masses on tiny springs. These springs bend whenever an inertial force acts, being able to measure it. It can measure the forces applied to the device, either the earth's gravity or the forces resulting from shaking the device [10].

- Gyroscope, like the accelerometer, it constituted by a set of tiny masses on tiny springs. In this case, instead of measuring the acceleration they measure the rotation force, or the Coriolis force. The Coriolis force acts only when the device is rotating, which enables the measurement of the speed rotation of the device. It is not possible to measure directly the angle of the device using the gyroscope, unless the values are integrated 
over time. When the device is stationary the gyroscope will measure zero [10].

- Magnetometer is a quite complex sensor, and depending on the manufacturer and architecture it may be implemented using the Hall effect, Lorentz force or even magneto-resistive materials. The most common solution is the Hall effect that consists in passing a current through a wire. Magnetometers, like the compass, are used to measure the absolute magnetic field of the Earth. The values measured by the magnetometer change based on the current local magnetic environment [10].

In addition to these sensors, Android has some built-in sensor fusion techniques available by software and hardware. Sensor fusion is a process of combining multiple sensors data in order to obtain more accurate results [10]. With these techniques it is possible to smooth the noise produced by sensors like the accelerometer, or compute device's orientation relative to the Earth. In this sense, accelerations due to gravity can be discriminated from those due to movement, therefore improving the accuracy of measurements. On Android the result of sensor fusion is used as a sensor, e.g. the gravity sensor that gives the value of the gravity after being processed according to the accelerometer readings. Modern devices include virtual or hardware sensors capable of measuring data with respect to the global coordinate system.

The prototype construction involves two distinct phases. The first one, more exploratory, involves recording sensor data, analyze the data gathered and explore different positions for the smartphone. The second phase is more technical, involving the design of the algorithms to process the movements and provide the correct feedback to the users.

\section{A. Movement Analysis}

In this phase it was necessary to find a way to collect and analyze the data gathered from the inertial sensors. To record this data, was built a simple Android application was built. This application has access to the data read by the sensors and saves the information in an external file. Acquisition of signals can be performed using different sampling rates. In Android, it is possible to define four different default rates: the Fastest, the Game, the UI and, finally, the Normal [10].

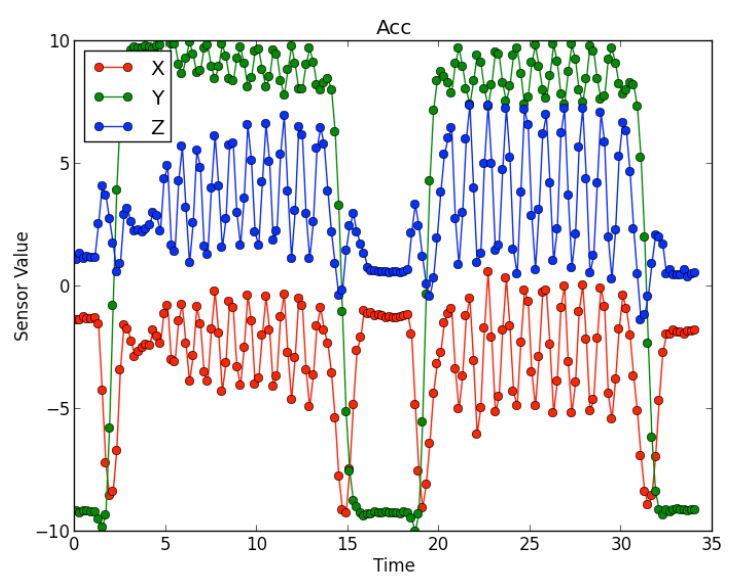

Fig. 1. Upper Limb Exercise recorded with accelerometer.
After recording the exercises with Android it was necessary to process that information. A program in Python was used to read files and process the recorded signals. To obtain a visual analysis of the results it was used a Python 2D plotting library, the matplotlib. With this approach it was possible to build a plot for each sensor, exercise and experimental positioning of the smartphone.

It was also necessary to define the most appropriated axis or axes to process data. To understand this need we can look to the Fig. 1 where it is possible to see clearly the variation produced in each axis of the accelerometer during the execution of the upper limb exercise. In this movement a variation is produced by the gravity on the $\mathrm{Y}$-axis that goes from near $-10 \mathrm{~m} / \mathrm{s}^{2}$ at the initial position to $10 \mathrm{~m} / \mathrm{s}^{2}$ when the exercise position is reached. At this stage, the arms are forced to stay in this position with small forcing movements, which are more easily readable on the Z-axis of gravity.

In this process it was also required to define the best position to attach the smartphone during the execution of exercises, taking into account comfort and the quality of recorded sensor data. Based on exercises characteristics, few possible positions would be admitted, for example, waist, arms, legs or hands. To facilitate the set up of each exercise and their sequence, the less number of locations are considered to attach the smartphone, the better. As the fall prevention program chosen to support this application is mainly focused on arms and legs movements, they could be divided into two groups. With this division it was possible to have only two locations for the smartphone, one on the thigh and the other on the wrist (Fig. 2). In both positions the smartphone is strap to the user with an armband.
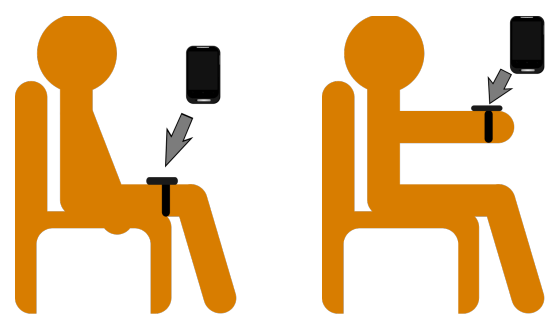

Fig. 2. Smartphone position on thigh (left image) and on wrist (right image)

\section{B. Signal Processing}

After defining the smartphone position based on the recorded data and with a set of valid values from the sensors it was necessary to start creating the algorithms for real-time analysis. The first step was to define the most appropriated sensor rate. The normal rate was chosen for sensor data sampling, as this frequency is able to capture all the information that is present in the movements that constitute the exercises. Also, this will save battery on the device. This rate works perfectly for most of the exercises, except for the ankle movements exercise, where the delay of the normal rate is too big to detect small variations.

This occurs due to the positioning of the smartphone on the thigh. In this position, it is possible to detect the upper and 
down movement of the thigh, produced as a consequence of the ankle flexion movement when the user is sitting on a chair. Therefore it was necessary to use the fastest rate, to detect and process those variations. In this case, in order to obtain better results it was necessary to smooth the values recorded from the sensors. Using a low-pass filtering technique, in this case weighted smoothing it was possible to obtain a more uniform set of readings. This technique involves weighting the newest value against the old mean, such that [10]:

$$
\text { NewValue }=\text { LastValue }+x_{i} * a-\text { LastValue } * a
$$

Where the $x_{i}$ is the value read from the sensor, and $a$ is the smoothing value. In this case the value of $a$ is 0,1 , which is a decent choice for a smooth plot. In addition to the filter it was also necessary to amplify the signal. The original signal is squared in order to maintain the signal curvature unchanged. In order to have only positive values before squaring the signal, a safe value is added. Therefore the $x_{i}$ is:

$$
x_{i=}(\text { SensorValue }+ \text { SafeValue })^{2}
$$

This signal processing produces a much linear plot, as it is visible on the Fig. 3. In this case, it is possible to see clearly the four local maximums of the Y-axis gravity corresponding to four plantar flexion movements. The main problem associated to this approach is that the values on the graphic cannot be easily associated to the normal value of gravitational acceleration, around $9,8 \mathrm{~m} / \mathrm{s}^{2}$.

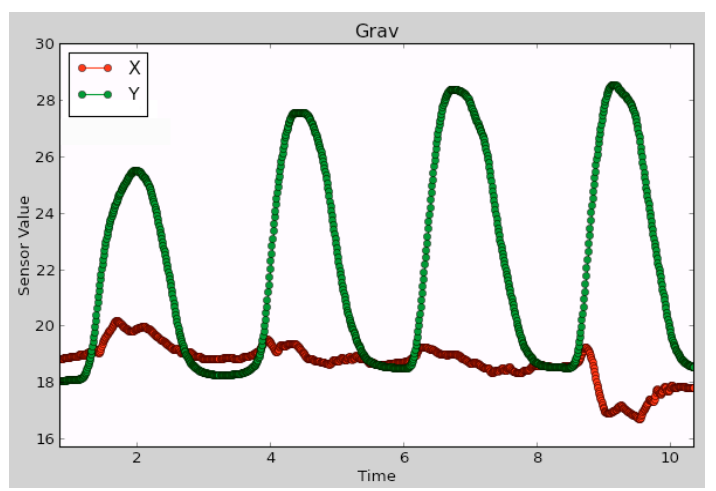

Fig. 3. Plantar Flexion recorded with gravity sensor.

All the exercises are evaluated in real-time therefore realtime processing is required. Real-time analysis is made by comparison of sensors' readings with fixed threshold values able to detect and confirm the current orientation of the smartphone, which may vary in line with the movement. Once again, the ankle movements' exercise is an exception, since threshold values used may vary according to the initial orientation of the smartphone. To overcome this problem, each time the exercise starts the initial position is processed, and then the signal amplitude is evaluated taking into account the initial orientation of the device.

The linear acceleration sensor is used to detect the number of times a person forces to maintain a certain position, for example, the number the forcing movements that occurs on the upper limb elevation. As this movement produces low accelerations, the influence of gravity could not be considered, in order to obtain more accurate readings specifically related to movement.

On exercises like the upper limb elevation or reaching forward, the readings from the gravity sensor range from negative to positive values, according to the smartphone's orientation relative to the vertical of the earth, being easy to detect when and how the movement is performed. Another sensor used in this application is the rotation vector, which is capable of detecting the device rotation during the upper limb elevation.

Each exercise begins in a different initial position that must be matched to a set of pre-defined values so that the person is always forced to begin the exercise correctly, in the pre-defined position. To do this, the smartphone orientation is perceived and, when it matches the desired orientation (by means of predefined values), the exercise can begin. At this moment, the application starts to collect all the metrics associated with the corresponding exercise. These metrics are summarized in the Table 1.

\begin{tabular}{|c|c|}
\hline Exercise & Metrics Collected \\
\hline $\begin{array}{l}\text { Extension of the } \\
\text { thoracic spine }\end{array}$ & $\begin{array}{l}\text { Number of repetitions; } \\
\text { Time held in position; } \\
\text { Number of forcing movements in } \\
\text { position; }\end{array}$ \\
\hline $\begin{array}{l}\text { Upper Limb } \\
\text { Elevation }\end{array}$ & $\begin{array}{l}\text { Number of repetitions; } \\
\text { Time held in position; } \\
\text { Number of forcing movements in } \\
\text { position; }\end{array}$ \\
\hline Ankle Movements & $\begin{array}{l}\text { Number of ankle dorsiflexion and } \\
\text { plantar flexion during } 10 \text { seconds; }\end{array}$ \\
\hline Sit to Stand & $\begin{array}{l}\text { Number of stands and sit ups; } \\
\text { Average length and standard deviation } \\
\text { of the cycle sit up; } \\
\text { Average length and standard deviation } \\
\text { of the cycle stand to sit; } \\
\text { Average length and standard deviation } \\
\text { of the complete cycle; }\end{array}$ \\
\hline Single Leg Stance & Time held in position; \\
\hline Reaching Forward & $\begin{array}{l}\text { Time held in position; } \\
\text { Number of repetitions; } \\
\text { Angle made by the arm with the } \\
\text { vertical; }\end{array}$ \\
\hline
\end{tabular}

TABLE I. EXERCISE METRICS

\section{PRELIMINARy EVAluation AND LESSONS LEARNED}

At this moment the algorithms to measure and collect metrics from the exercises only have a very preliminary and sketchy evaluation that was performed during the program development. But it is possible to say that the set of exercises performed with the smartphone on the leg are less propitious to involuntary errors. On the other hand the set of the exercises with focus on the arm are much more unstable, as much more random movements can be created by arms and therefore introduce misleading information that can be processed inaccurately. 
At this point of the project there are already some reflections regarding the use of the sensors available on Android to evaluate the exercises. In fact, several physical differences exist between each individual; also, for the execution of tests, each individual can use different chairs with different heights. In addition to it, between repetitions the user might place his legs in different initial positions during the same exercise set. This required the adjustment of thresholds for each situation, which requires some time in a static position to get calibration data able to adjust the upcoming sensor readings according to the initial smartphone positioning. However users may not be willing to wait for the calibration process, therefore these adjustments must be done in background during the exercise execution. The main drawback of doing this evaluation on the background is the small number of samples that can be collected and processed during the exercise execution.

\section{MAIN CONTRIBUTIONS}

In this paper a method is presented to be used as a fallprevention solution, using the smartphone. Fall-prevention exercises detailed on Argel de Melo, C. programme [7] were adapted to the smartphone, offering the means to guide and evaluate the exercises at home with increased motivation to the user. This study provides the first steps in this adaptation.

The smartphone approach isn't too expensive and nowadays almost everyone has a smartphone that can be used for fall prevention purposes. Exercise's evaluation will enable the monitoring of several parameters, which can be used to monitor the patient's evolution. Therefore, it will enable collecting, processing and measure fall prevention exercises using just a single device, the smartphone.

\section{CONCLUSIONS AND FUTURE WORK}

Despite being a work in progress this application can be a promising contribution to fall prevention. A full validation of the exercise's algorithms performance, detection, evaluation and feedback are still required to ensure that proper, useful and reliable metrics are being collected in the exercises.

In overall this is a new approach to guide and evaluate fall prevention exercises that in combination with a serious game tries to fulfill the lack of motivation that these exercises may generate on the elderly. Keep the user motivated through time is essential otherwise the effectiveness of the programme will be compromised. Nevertheless it is necessary to ensure that these exercises are totally safe to be performed alone without any risk to the patient.

It is expected that this prototype will soon evolve into a serious game, offering an attractive design and a scoring system that may motivate the user to play The game design, that is being thought, has two very distinctive approaches. One requires a set-top box (for example a Google TV) connected to the smartphone where the user can move objects shown in the television using the smartphone movements performed during the exercise. The other alternative is to use the mobile phone screen as interface but this has some limitations, mainly because during the exercise execution the user is not able to correctly see the screen. To overcome this problem the interaction may be done through audio, playing specific sounds at key positions of the exercise execution.

After the adaptation to a serious game it is important to test and validate the game design with the target audience, in this case with elderly people. In this validation, the most important aspect that requires to be validated is the motivation that the game will produce on the elderly.

Finally, it is relevant to mention the biggest handicap of this prototype, which is the single member evaluation. The exercises must be performed using both limbs (upper or lower), but the smartphone is only capable of evaluating one limb (as it is attached solely to one of our limbs). This problem can be overcome using external sensors. New sensors could be placed on the user's leg or arm reducing the need of changing the mobile phone position according to the exercise performed and at the same time evaluate both limbs. The main drawback of this approach is the addition of an extra device that also adds an extra cost to the system.

\section{ACKNOWLEDGMENT}

We would like to thank to therapist Cristina Melo for all of her support and willingness to help us understanding the exercises programme.

\section{REFERENCES}

[1] I.P. Instituto Nacional de Estatísticas. Indicadores sociais 2011.

[2] Centers for Disease Control and Prevention. Falls among older adults: An overview.

[3] World Health Organization. Who global report on falls prevention in older age.

[4] JeffreyHalter,JosephOuslander,MaryTinetti,StephanieStudenski,KevinH igh,and Sanjay Asthana. Hazzard's Geriatric Medicine and Gerontology, Sixth Edition (Prin- ciples of Geriatric Medicine \& Gerontology). McGraw-Hill Professional, 2009.

[5] Otago Exercise Programme to prevent falls in older adults. A homebased, individually tailored strength and balance retraining programme. Prevention, Care, Recovery, 2003.

[6] FAME. Fitness and Mobility Exercise Program: A community-based Group Exercise Program for People Living with Stroke, 2006.

[7] Argel de Melo, C., Kuisma, R., \& Trew, M. A preventive, specific and moderate exercise programme on fall risk factors in older portuguese people. The Journal of Nutrition, Health and Aging, 2011.

[8] Ed Burnette. Hello, Android: Introducing Google's Mobile Development Platform. Pragmatic Programmers, LLC, 2010.

[9] Dave MacLean Sayed Hashimi, Satya Komatineni. Pro Android 3. Apress, 2011.

[10] G. Milette and A. Stroud. Professional Android Sensor Programming. Wiley, 2010.

[11] G. Robert Whitcomb. Computer games for the elderly. SIGCAS Comput. Soc., August 1990.

[12] S T Smith, C Sherrington, S Studenski, D Schoene, and S R Lord. A novel Dance Dance Revolution (DDR) system for in-home training of stepping ability: basic pa- rameters of system use by older adults. British journal of sports medicine, May 2011. 